TITLE:

Crystal structure of peroxisomal
targeting signal-2 bound to its
receptor complex Pex $7 p-P e x 21 p$

$\operatorname{AUTHOR}(S):$

Pan, Dongqing; Nakatsu, Toru; Kato, Hiroaki

CITATION:

Pan, Dongqing ... [et al]. Crystal structure of peroxisomal targeting signal-2 bound to its receptor complex

Pex7p-Pex21p. Nature Structural \& Molecular Biology 2013

ISSUE DATE:

2013-06-30

URL:

http://hdl.handle.net/2433/175497

RIGHT:

(c) 2013 Nature Publishing Group, a division of Macmillan Publishers Limited. All Rights Reserved.; 許諾条件により本文は2013-12-30に公開.; This is not the published version. Please cite only the published version.; この論文は出版社版でありません。引用の際には 出版社版をご確認ご利用ください。 


\section{Crystal structure of peroxisomal targeting signal-2 bound to its receptor complex}

\section{$\operatorname{Pex} 7 p-P e x 21 p$}

Dongqing $\operatorname{Pan}^{1}$, Toru Nakatsu ${ }^{1,2}$, and Hiroaki Kato ${ }^{1,2}$

${ }^{1}$ Department of Structural Biology, Graduate School of Pharmaceutical Sciences, Kyoto

University, 46-29 Yoshida-Shimoadachi, Sakyo-ku, Kyoto 606-8501, Japan.

${ }^{2}$ RIKEN SPring-8 Center, 1-1-1, Kouto, Sayo, Hyogo 679-5148, Japan.

Correspondence should be addressed to Dongqing Pan (pan.dongqing@pharm.kyoto-u.ac.jp)

or Hiroaki Kato (katohiro@pharm.kyoto-u.ac.jp).

Running title: Structural basis for PTS2 recognition 


\section{Abstract}

Appropriate targeting of matrix proteins to peroxisomes is mainly directed by two types of peroxisomal targeting signals, PTS1 and PTS2. Although the basis of PTS1 recognition has been revealed by structural studies, that of PTS2 recognition remains elusive. Here, we present the crystal structure of a hetero-trimeric PTS2-recognition complex from Saccharomyces cerevisiae, containing Pex7p, the C-terminal region of Pex $21 \mathrm{p}$, and the PTS2 of the peroxisomal 3-ketoacyl-CoA thiolase. Pex7p forms a beta-propeller structure and provides a platform for cooperative interactions with both the amphipathic PTS2 helix and Pex21p. The C-terminal region of Pex21p directly covers the hydrophobic surfaces of both Pex7p and PTS2, and the resulting hydrophobic core is the primary determinant of stable complex formation. Together with in vivo and in vitro functional assays of Pex $7 \mathrm{p}$ and Pex $21 \mathrm{p}$ variants, our findings reveal the molecular mechanism of PTS2 recognition. 


\section{INTRODUCTION}

Many proteins use targeting signals to reach the appropriate organelles. Organelle-specific receptor proteins recognize these targeting signals by direct protein-protein interactions. This is also the case with peroxisomes, single membrane-bound organelles containing enzymes involved in various metabolic pathways such as hydrogen peroxide detoxification and $\beta$-oxidation of fatty acids ${ }^{1}$. More than twenty proteins work in concert to assemble functional peroxisomes. These proteins are named peroxins, and are encoded by the PEX genes ${ }^{2,3}$. In human, defects in peroxins disrupt import of essential enzymes into peroxisomes, resulting in a group of human diseases known as the peroxisomal biogenesis disorders (PBDs) ${ }^{4}$. The receptor proteins that recognize peroxisomal targeting signals are crucial peroxins.

There are two types of targeting signals for peroxisomal matrix proteins: peroxisomal targeting signal-1 (PTS1) at C-termini, and peroxisomal targeting signal-2 (PTS2) near $\mathrm{N}$-termini ${ }^{2}$. PTS 1 is recognized by the peroxin Pex5p, and PTS2 is recognized by the peroxin Pex7p together with a co-receptor peroxin. Crystal structures of the PTS1-binding domain of Pex $5 p$ have been solved in apo-form ${ }^{5}$, with a PTS1 peptide ${ }^{6}$ or with a PTS1-cargo (mSCP2) . $^{5}$. On the other hand, no crystal structure of Pex7p or the PTS2-interaction domain of the co-receptor peroxin, ligated with or without PTS2, has been reported to date; consequently, 
many questions remain unsolved $d^{7,8}$.

One important question regards what interactions between PTS2 and the receptors determine the characteristic sequence motif of PTS2. The PTS2 sequence was initially identified in rat peroxisomal thiolase ${ }^{9,10}$. Later, the sequence motif of PTS2 was refined to $\mathrm{R}-[\mathrm{L} / \mathrm{V} / \mathrm{L} / \mathrm{Q}]-\mathrm{xx}-[\mathrm{L} / \mathrm{V} / \mathrm{I} / \mathrm{H}]-[\mathrm{L} / \mathrm{S} / \mathrm{G} / \mathrm{A}]-\mathrm{x}-[\mathrm{H} / \mathrm{Q}]-[\mathrm{L} / \mathrm{A}] \quad(\mathrm{x}=$ any residue $)$ by bioinformatics analysis of available functional PTS2 sequences ${ }^{11}$. Positions 2,5 , and 9 of this motif are mostly limited to hydrophobic residues whereas positions 1 and 8 are limited to hydrophilic residues. In order to explain these sequence constraints, the detailed interactions between PTS2 and its receptors must be determined.

Another question regards how Pex7p provides the binding site for PTS2. Pex $7 p$ is an evolutionarily conserved soluble protein containing six WD40 repeats ${ }^{12-20}$. The first Pex $7 p$ identified was S. cerevisiae Pex7p (also known as Peb1p or Pas7p), which was shown to be the receptor of Fox3p (also known as Pot1p) ${ }^{12,13,21}$. Fox3p contains a functional PTS2 at its $\mathrm{N}$-terminus ${ }^{21,22}$ and functions as a 3-ketoacyl-CoA thiolase (EC 2.3.1.16) at the final step of the $\beta$-oxidation ${ }^{1}$. Human Pex $7 \mathrm{p}$ was identified as the homolog of S. cerevisiae Pex $7 \mathrm{p}$ and linked to a fatal PBD, rhizomelic chondrodysplasia punctata type $1(\mathrm{RCDP} 1)^{14-16,23,24}$. Since Pex7p is a WD40 protein, its structure has been modeled using the structures of other WD40 proteins, and 
the possible interactions between Pex7p and PTS2 has been proposed ${ }^{25}$. However, we still lack a complete view of the interactions between Pex7p and PTS2.

A more challenging, but also intriguing, question regards how the co-receptor peroxin assists Pex7p in PTS2 recognition. The co-receptor peroxin is species-specific. Paralogous peroxins, Pex18p and Pex21p, act as the co-receptor of Pex $7 p$ in S. cerevisiae ${ }^{26}$, and their homolog Pex20p exists in other fungi ${ }^{20,27,28}$. The PTS1 receptor, Pex5p, also acts as the co-receptor of Pex7p in Arabidopsis thaliana ${ }^{19,29}$ and in mammals ${ }^{30-32}$. The domain structures of these co-receptor peroxins share common features: First, their N-terminal domains contain a conserved motif ${ }^{27,33}$ that is ubiquitinated during the recycling of receptors from peroxisomal membrane to cytosol ${ }^{34,35}$. Second, the Pex14p-binding motif (Wxxx[F/Y]) interacts with Pex $14 \mathrm{p}^{36}$, a peroxin that forms a docking complex on the peroxisomal membrane. Third, the Pex7p-binding domain (Pex7pBD) is essential for the interaction with Pex7p and the import of PTS2-cargos into peroxisomes ${ }^{27,32,33}$. In Pex18p, Pex21p, and Pex20p, Pex7pBD resides close to the C-termini, whereas in Pex5p, an additional PTS1-binding domain flanks the C-terminal side of Pex7pBD ${ }^{27}$. Pex7pBD seems to be the most important region for interaction with Pex7p, but where does Pex7pBD bind on Pex7p, and how does it support PTS2-cargo transport?

Since their discoveries, PTS2, Pex7p, and the co-receptor peroxins have been studied and 
characterized. However, the details of the interactions among the three factors remain unclear.

To understand the mechanism of PTS2 recognition and the molecular basis of RCDP1, we solved the crystal structure of a PTS2-recognition complex from S. cerevisiae. The structure contains Pex7p, the C-terminal region of Pex21p (Lys190-Asp288; hereafter referred to as Pex $21 p C$ ), and the N-terminal 15 residues of Fox $3 p$ (hereafter referred to as Fox $3 p N$ ), and reveals the conserved mechanism of PTS2 recognition and its differences with other $\mathrm{N}$-terminal targeting signals. 


\section{RESULTS}

\section{Preparation of Pex7p-Pex21pC-Fox3pN-MBP complex}

We purified the ternary complex containing Pex $7 \mathrm{p}$, Pex21pC, and Fox $3 \mathrm{pN}-\mathrm{MBP}$ by mixing the three proteins after purification of individual components. Pex $7 \mathrm{p}$, which was difficult to obtain in soluble form using an Escherichia coli expression system, was expressed in Pichia pastoris as GST-fusion protein. Well-diffracting plate crystals grew when a Pex7p mutant with a nine-residue deletion $(\Delta 257-265)$ was used instead of wild-type Pex7p (Fig. 1, Supplementary Fig. 1). Pex21pC was sufficient to form the ternary complex and was more resistant to degradation than the homologous region of Pex18p; it was therefore chosen for crystallization. Fox3pN-MBP, used instead of full-length Fox3p, was constructed by attaching Fox $3 \mathrm{pN}$ to the N-terminus of the maltose-binding protein (MBP) from E. coli by a two-residue linker (Arg-Ser) (Fig. 1a).

Pex $7 \mathrm{p}$, Pex $21 \mathrm{pC}$, and Fox $3 \mathrm{p}$ exhibited cooperative complex formation, as demonstrated by pull-down experiments using wild-type Pex7p (or GST-Pex7p), Pex21pC (or MBP-Pex21pC), and Fox3p (Fig. 2). The ternary complex containing Pex7p, Pex21pC, and Fox3p was much more stable than any of the binary complexes. Although we did not detect the 
binary interaction of Fox3p with Pex7p in the buffer with $300 \mathrm{mM} \mathrm{NaCl}$ by the pull-down experiment, we observed weak but specific binding of Fox3p to Pex7p in the buffer with 50 $\mathrm{mM} \mathrm{NaCl}$ (Supplementary Fig. 2).

\section{Overall structure of the hetero-trimeric complex}

The hetero-trimeric structure of Pex7p-Pex $21 \mathrm{pC}-$ Fox $3 \mathrm{pN}-\mathrm{MBP}$ was solved by molecular replacement using crystal structures of MBP and WDR5 as search models. The overall electron-density map was clear (Supplementary Fig. 3), allowing us to construct atomic models for all regions of Pex7p, Pex21pC, and Fox3pN-MBP except for the disordered loops of Pex7p (DL1, Lys164-Arg174; DL2, Leu253-Ser272; DL3, Asp317-Tyr323) and Pex21pC (DL1, Lys190-Gln196; DL2, Pro212-Leu223; DL3, Lys252-Ala259) (Fig. 1c, Supplementary Fig. 1a,b). Only one hetero-trimer exists in the crystallographic asymmetric unit, and the model was refined at $1.8 \AA$ resolution to a free $R$-factor of $22.4 \%$ (Table 1 ).

The resulting structure revealed the characteristic assembly of the three proteins (Fig. $1 \mathrm{~b}, \mathrm{c})$. Pex $7 \mathrm{p}$ forms a ring structure with a seven-bladed $\beta$-propeller fold. Pex $21 \mathrm{pC}$ consists of three parts: a cluster of three $\alpha$-helices $(\alpha 1-3)$, a small three-stranded $\beta$-sheet $(\beta 1-3)$, and a stretched C-terminal loop. The helical cluster and the $\beta$-sheet of Pex $21 \mathrm{pC}$ bind on the rim of the 
top surface of Pex7p, and they cooperatively form a binding pocket for Fox3pN. The C-terminal loop of Pex $21 \mathrm{pC}$ extends along the side of Pex $7 \mathrm{p}$ and does not interact with Fox $3 \mathrm{pN}$. Fox $3 \mathrm{pN}$ adopts an $\alpha$-helical conformation and stretches from the globular region of MBP into the binding pocket prepared by Pex $7 \mathrm{p}$ and Pex $21 \mathrm{pC}$. The buried surface area of Fox $3 \mathrm{pN}(1,240$ $\left.\AA^{2}\right)$ in the pocket accounts for more than $70 \%$ of its total solvent-accessible surface area $(1,740$ $\left.\AA^{2}\right)$.

\section{Special motif of Pex7p and Pex7p-Pex21p complex formation}

The crystal structure revealed structural features important for Pex $7 \mathrm{p}-\mathrm{Pex} 21 \mathrm{p}$ complex formation. Although the framework of Pex7p is the same as that of typical WD40 proteins ${ }^{37}$, it contains a special region at its $\mathrm{N}$-terminus. The $\mathrm{N}$-terminal 44 residues of Pex $7 \mathrm{p}$ have low sequence similarity to other WD40 motifs ${ }^{13}$, but this region can nonetheless assume a WD40-like fold and complete the ring structure (Fig. 1c, Supplementary Fig. 4ab). In this $\mathrm{N}$-terminal region, the loop between $\beta$-strand 1B and 1C (Asn31-Asn37) is longer than other adjacent loops composing the top surface of Pex7p, and thus forms a bulge (Fig. 1c, 3a, Supplementary Fig. 4a), hereafter referred as to the bulge loop. The bulge loop contains a six-residue consensus motif, [N/H]-[F/Y]-G-[L/I]-[V/L/I/S/A]-G, whose length and 
composition are conserved in Pex7p homologs (Supplementary Fig. 1a). By partially adopting a 310 -helix structure, the bulge loop exposes the hydrophobic residues Phe32, Leu34, and Val35 on its surface (Fig. 3b). When Pex $7 \mathrm{p}$ forms a complex with Pex $21 \mathrm{pC}$, this protruding hydrophobic bulge loop is covered by the hydrophobic pocket of Pex $21 \mathrm{pC}$ formed at the hinge region between $\alpha 3$ and $\beta 1$ (Fig. 3b).

The bulge loop constitutes half of a hydrophobic ridge on the top surface of Pex7p (Fig. 3a) that consists of residues from blade 1 (the bulge loop), blade 6 (Leu284, Tyr304, Met306), and blade 7 (Phe344, Trp364) (Supplementary Fig. 4a). The hydrophobic ridge contacts the hydrophobic surface of Pex21p, which contains nine hydrophobic residues: Cys210 on $\alpha 1$; Val227 and Leu231 on $\alpha 2$; Phe236, Ile237, Leu239, and Met240 on $\alpha 3$; Leu250 on $\beta 1$; and Leu262 on $\beta 2$ (Fig. 3b, Supplementary Fig. 4c). Four residues of Pex7p, Phe32, Leu34, Phe344, and Trp364, surround Pex21p Phe236 (Fig. 3b, Supplementary Fig. 3b), which is highly conserved among the co-receptor peroxins (Supplementary Fig. 1bc).

Pex $7 \mathrm{p}$ has another characteristic region involved in binding with Pex21pC. An acidic patch is formed at the side of the hydrophobic ridge on blades 6 and 7 (Fig. 3a). This acidic patch consists of two components: the side chain of Pex $7 p$ Glu343 and the clustered main-chain $\mathrm{C}=\mathrm{O}$ groups of Pex7p Met306, Thr339, and His341 (Fig. 3a, Supplementary Fig. 4a). The side 
chain of Pex7p Glu343 interacts electrostatically with the side-chain $\mathrm{OH}$ group of Pex $21 \mathrm{p}$ Ser234 and the main-chain NH group of Pex21p Lys235 (Fig. 3b). Because Pex21p Ser234 and Lys 235 are located in the $\mathrm{N}$-terminal portion of $\alpha 3$, they are positively charged by the dipole effect of the $\alpha$-helix. The clustered main-chain $\mathrm{C}=\mathrm{O}$ groups of Pex7p Met306, Thr339, and His341 are in range to form hydrogen bonds with Pex21p Lys230 (Fig. 3b).

Most of the residues forming the hydrophobic and electrostatic interfaces between Pex $7 \mathrm{p}$ and Pex21pC are conserved among the corresponding homologs (Supplementary Fig. 1).

\section{PTS2 recognition by cooperation of Pex7p and Pex21p}

The $\alpha$-helix of Fox3pN is amphipathic. Fox3p Met1, Leu5, Ile8, Leu12, and Val13 form the hydrophobic surface, whereas the remaining residues form the hydrophilic surface (Fig. 4a). As a result, the key residues of PTS2 are separated in two groups: the hydrophilic key residues (Fox3p Arg4, His11) and the hydrophobic key residues (Fox3p Leu5, Ile8, Leu12).

The binding site of PTS 2 is a large cleft that holds the $\alpha$-helix of Fox $3 \mathrm{pN}$ and contains two minor grooves that accept side chains protruding from the $\alpha$-helix (Fig. 1c, 4bc). One groove is hydrophilic and the other is hydrophobic. The hydrophilic groove at the center of the top surface of Pex7p contains two pockets that accept the hydrophilic key residues of PTS2 (Fox3p 
Arg4 and His11) (Fig. 3a, 4c). Fox3p Arg4 is surrounded by the residues of Pex7p blades 1-3, and its guanidine group is fixed by formation of salt bridges with the carboxyl groups of two acidic residues, Pex7p Asp61 and Glu106 (Fig. 3a, 4b). Fox3p His11 is surrounded by the residues of Pex $7 \mathrm{p}$ blades 4-6, and its imidazole ring is fixed by formation of hydrogen bonds with Pex7p Tyr178, Glu222, and Tyr304. When Fox3p Arg4 and His11 bind to the top surface of Pex $7 \mathrm{p}$ in the correct orientation, the hydrophobic residues of Fox $3 \mathrm{pN}$ consequently fit into the hydrophobic groove (Fig. 4c), which is formed in between the hydrophobic interfaces of Pex7p and Pex21pC (Fig. 3a). All three hydrophobic key residues (Fox3p Leu5, Ile8, Leu12) of PTS2 are hidden inside the hydrophobic groove and form van der Waals contacts with Pex $21 \mathrm{p}$ Phe236 (Fig. 4bc, Supplementary Fig. 3b). Additionally, Fox3p Met1 is embedded in the site above the bulge loop (Fig. 3a, 4bc).

Insertion of the hydrophobic side chains of PTS2 to the hydrophobic groove completes a hydrophobic core around the central residue, Pex21p Phe236 (Fig. 4b). Other components of the hydrophobic core are the hydrophobic residues that form the hydrophobic interfaces of Pex $7 p$ and Pex21p described above (Fig. 3b).

The residues of Pex $7 \mathrm{p}$ and Pex21pC that form the binding site for PTS2 are well conserved among the corresponding homologs (Supplementary Fig. 1). In particular, the $\alpha 1$ 
helix of Pex $21 \mathrm{pC}$, which forms a lid to cover PTS2, is also a conserved region among the co-receptor peroxins as with Pex21p $\alpha 2$ and $\alpha 3$, which compose Pex7pBD ${ }^{8}$ (Supplementary Fig. $1 b)$.

\section{In vitro and in vivo assays of Pex $7 p$ and Pex21p mutants}

To examine the functional importance of the interaction modules of Pex $21 \mathrm{p}$ and Pex $7 \mathrm{p}$ in ternary complex formation and PTS2-cargo transport, we performed in vitro and in vivo functional assays. For the in vitro assays, we conducted pull-down experiments using amylose resin with purified MBP-Pex21pC (or its variants), Pex7p (or its variants), and Fox3p (Fig. 5ab). For the in vivo assays, S. cerevisiae gene deletion strains of Pex7p alone (4pex7) or both Pex18p and Pex21p (4pex184pex21) were created from wild-type strain BY20134 (W303-1A background). C-terminally His $_{6}$-tagged Pex $7 p, P e x 21 p$, and their variants were expressed in the deletion strains, and the growth of these derivative strains on oleic-acid medium (SCOT agar plate) was examined. As reported previously ${ }^{13,26}, \Delta p e x 7$ and $\Delta$ pex18 4 pex 21 exhibited growth defects on SCOT plates due to the inability to import sufficient Fox3p into peroxisomes, whereas $\triangle p e x 7$ expressing wild-type Pex $7 \mathrm{p}$ and $\triangle$ pex184pex 21 expressing Pex $21 \mathrm{p}$ exhibited normal growth (Fig. 5c). Simultaneously, Fox3pN-EGFP and mCherry-PTS1 (PTS1 = 
Ser-Lys-Leu) were co-expressed in all strains, and their localizations were observed using a confocal microscope (Supplementary Fig. 5a). Expressed Pex7p and Pex21p variants were detected by western blotting (Supplementary Fig. 5b).

To investigate the importance of the hydrophobic core, we replaced the central residue Pex21p Phe236 and the adjacent conserved residues (Pex7p Phe32, Leu34, Phe344, and Trp364) with Ala or Asp. Single-Ala mutants of these residues did not have significant effects on formation of the ternary complex (Fig. 5b). However, when we mutated Pex21p Phe236 or Pex7p Leu34 to Asp (Pex21p F236D, Pex7p L34D), or simultaneously mutated two nearby residues of Pex7p to Ala (Pex7p F32A L34A, F344A W364A), these mutants exhibited clear defects in complex formation (Fig. 5a,b). These mutants also failed to restore growth of $4 p e x 7$ or Apex184pex21 on SCOT plates (Fig. 5c) and were unable to restore localization of Fox3pN-EGFP to peroxisomes (Supplementary Fig. 5a). Among the single-Ala mutants, the Pex7p L34A and F344A mutants were both able to import enough amount of Fox3p into peroxisomes to restore growth of $\triangle p e x 7$ on SCOT plates (Fig. 5c), but the efficiency of Fox3pN-EGFP transport was not sufficient for formation of clear spots (Supplementary Fig. 5a). The Pex21p F236A mutant was less able to restore growth of 4 pex184pex21 on SCOT plates (Fig. 5c), although we did not observe a clear effect of this mutant on complex formation (Fig. 
5a). Pex $21 \mathrm{p}$ Ile206, located on the $\alpha 1$ helix, is also a component of the hydrophobic core. The Pex21p I206D mutant exhibited lower affinity for Pex7p and Fox3p (Fig. 5a) and was unable to restore growth of $\Delta$ pex $18 \Delta$ pex 21 on SCOT plates (Fig. 5c). The results of Pex21p I206D were similar to those of the Pex21p $\Delta \alpha 1$ mutant $(\Delta 197-211)$ (Fig. 5a,c). Mutations of residues outside the hydrophobic core (Pex21p I202D, K230E) did not affect complex formation (Fig. 5a), and these mutants were able to restore growth of 4 pex184pex21 on SCOT plates (Fig. 5c). Two Pex21p deletion mutants, $\Delta \mathrm{L}(\Delta 214-229)$ and $\Delta \mathrm{C}(\Delta 247-288)$, were able to restore growth of $\triangle$ pex184pex 21 on SCOT plates (Fig. 5c). However, the deletion of the 42 C-terminal residues of the Pex21p $\Delta \mathrm{C}$ decreased the affinity of Pex21pC for Pex $7 p$ and Fox $3 p$ (Fig. 5a).

We next examined the role of Pex $7 \mathrm{p}$ residues that form electrostatic interactions with the hydrophilic key residues of PTS2 (Fox3p Arg4, His11). Consequently, we generated two gain-of-function variants of Pex7p that can recognize two artificial PTS2s containing Glu in place of either Arg4 or His11 in Fox3p. The mutated Pex7p containing D61R E106H lost the ability to import wild-type Fox $3 p$ into peroxisomes and failed to restore the growth of $\Delta p e x 7$ on SCOT plate (Fig. 5c). When we co-expressed the Pex7p D61R E106H mutant with the Fox3p R4E mutant, the transformant was able to grow on SCOT plate as rapidly as a strain expressing wild-type Pex7p (Fig. 5c). The same result was obtained in the case of a strain co-expressing 
the Pex7p Y178R Y304R and Fox3p H11E mutants. To exclude the possibility that the restoration of growth was due to overexpression of Fox $3 p$ mutants, we co-expressed the mutant proteins in the other combination. Neither the co-expression of Pex7p D61R E106H with Fox3p H11E nor co-expression of Pex7p Y178R Y304R with Fox3p R4E restored growth of $\triangle p e x 7$ on SCOT plates (Fig. 5c). 


\section{DISCUSSION}

The crystal structure we report here reveals the spatial organization of the Pex7p-Pex21pC-Fox $3 \mathrm{pN}$ complex and provides an explanation for the cooperative binding among Pex $7 \mathrm{p}$, Pex $21 \mathrm{pC}$, and Fox $3 \mathrm{p}$ observed in the pull-down experiments. Both Fox $3 \mathrm{pN}$ and Pex $21 \mathrm{pC}$ bind to the top surface of Pex $7 \mathrm{p}$, which is a common interaction site for WD40 proteins $^{38,39}$. On this surface, the hydrophobic residues of Pex $7 \mathrm{p}$, Pex $21 \mathrm{pC}$ and Fox $3 \mathrm{pN}$ cooperatively form a hydrophobic core around the central residue Pex21p Phe236. These hydrophobic residues are evolutionarily well conserved, which suggests that formation of the hydrophobic core is important for stabilizing the ternary complex. Any combination of the binary complexes (Pex7p-Fox3pN, Pex7p-Pex $21 \mathrm{pC}$, or Pex21pC-Fox3pN) leaves a part of the hydrophobic surface exposed to solution, destabilizing the binary complex. The electrostatic interactions between Pex7p and Pex21pC and between Pex7p and Fox $3 p N$ take place at both sides of the hydrophobic core, thus strengthening the hydrophobic effect and further stabilizing the ternary complex.

We confirmed the importance of the hydrophobic core on complex formation and PTS2-cargo transport by mutational analyses of residues inside and outside the hydrophobic core. Mutations of Pex21p Phe236 (F236A and F236D) were the most severe among the Ala 
and Asp mutants examined. The effects of Asp mutations decreased as residues contributed less to the rigidity of the hydrophobic core, in the following order (i.e., from greatest to lowest effect): Pex21p F236D, Pex7p L34D, Pex21p I206D, and Pex21p I202D. We assume that a minimal threshold of rigidity of the hydrophobic core is required for functional PTS2-cargo transport. Although some of the mutants (Pex7p F344A W364A, Pex21p I206D, and Pex21p $\Delta \alpha 1)$ exhibited only moderate defects in complex formation, they were unable to form hydrophobic cores with rigidities above this threshold. The decrease in affinity of the Pex $21 \mathrm{p}$ $\Delta \mathrm{C}$ mutant for Pex7p and Fox3p implies that the $42 \mathrm{C}$-terminal residues of Pex $21 \mathrm{p}$ also contribute to complex formation; however, these residues are not essential for the hydrophobic-core formation or PTS2-cargo transport. Assuming that the hydrophobic core is the primary determinant of stable complex formation, destabilization of the hydrophobic core is predicted to result in PTS2-cargo release. Further studies of kinetics and thermodynamic analyses using purified Pex7p and Pex $21 \mathrm{p}$ variants will be needed in order to identify the rigidity threshold of the hydrophobic core necessary for PTS2-cargo transport.

Our crystal structure indicates that the N-terminal 44 residues of Pex $7 p$ allow protrusion of the bulge loop while simultaneously folding into a WD40-like structure to complete the rigid $\beta$-propeller structure. This adaptation differentiates Pex7p from other WD40 proteins. The 
bulge loop is essential not only to form a landmark for Pex $21 \mathrm{p}$ but also to constitute a part of the binding site for PTS2. Among the single-amino acid substitutions in human Pex7p that cause RCDP1 $^{23,24}$ (Supplementary Fig. 1a), substitutions of His39 (Asn31 in S. cerevisiae) to Pro, and Gly41 (Gly33 in S. cerevisiae) to Val, are mutations on the bulge loop. This fact, together with the results of our mutation analyses of Pex7p Phe32 and Leu34, imply that the conserved shape and the surface property of the bulge loop are required for Pex $7 \mathrm{p}$ 's function.

The crystal structure suggests that Pex $21 \mathrm{p}$ strengthens the binding of Pex $7 \mathrm{p}$ to Fox $3 \mathrm{pN}$ by directly attaching its C-terminal region onto the PTS2 binding site, rather than by some allosteric mechanism. We consider that this direct binding mechanism is not $S$. cerevisiaespecific but rather common to the co-receptor peroxins of other species, because the regions of Pex $21 p$ essential for formation of the recognition complex (Pex $21 p \alpha 1, \alpha 2$, and $\alpha 3)$ are conserved among other co-receptor peroxins (Supplementary Fig. 1b). Pex $21 \mathrm{p} \alpha 1$ is reminiscent of the finger loop of SRP $54^{40}$, in that Pex $21 \mathrm{p} \alpha 1$ forms a hydrophobic lid to cover the hydrophobic surface of PTS2 and stabilize the recognition complex. The importance of Pex $21 \alpha 1$ can be derived from the result that $\operatorname{Pex} 21 \mathrm{p} \Delta \mathrm{C}$ and $\Delta \mathrm{L}$ mutants could restore growth of Apex184pex21 on SCOT plates whereas Pex21p $\Delta \alpha 1$ mutant couldn't. The Pex $7 \mathrm{p}-$ Fox $3 \mathrm{pN}$-bound structure of Pex $21 \mathrm{pC}$ is likely to be induced on the complex formation. 
If Pex $21 \mathrm{pC}$ is separated from Pex7p and Fox $3 \mathrm{pN}$ in aqueous solution, the exposure of the hydrophobic residues and the lack of intra-molecular interactions will be unfavorable to maintenance of the elongated structure of Pex $21 \mathrm{pC}$.

The crystal structure provides details regarding the complementarity between PTS2 and the receptor complex. Because PTS2 folds into an $\alpha$-helix, its hydrophobic key residues (Fox3p Leu5, Ile8, Leu12) fit into the hydrophobic groove formed by both Pex7p and Pex21p, and its hydrophilic key residues (Fox3p Arg4 and His11) fit into the hydrophilic groove on the top surface of Pex $7 \mathrm{p}$. Whereas the hydrophobic key residues of PTS2 are recognized mainly by spatial complementarity as parts of the hydrophobic core, the hydrophilic key residues of PTS2 are recognized both by spatial complementarity and by formation of salt bridges and hydrogen bonds with Pex7p. Other helical N-terminal targeting signals, such as the signal peptide ${ }^{40}$ and mitochondrial targeting signal (MTS ${ }^{41}$, also contain hydrophobic residues in their sequence motifs. However, the receptor proteins of the signal peptide and MTS (SRP54 and Tom20, respectively) do not recognize any hydrophilic residue as specifically as Pex $7 \mathrm{p}-\mathrm{Pex} 21 \mathrm{p}$ does. The PTS2 system shares this characteristic with the PTS1 system, in which basic key residue of the PTS1 sequence motif $\left(-[\mathrm{S} / \mathrm{A} / \mathrm{C}]-[\mathrm{K} / \mathrm{H} / \mathrm{R}]-[\mathrm{L} / \mathrm{M}]-\mathrm{CO}_{2}{ }^{-}\right)$is specifically recognized by Pex $5 \mathrm{p}^{5,6}$. It is reported that a mutated PTS1 peptide (Leu-Gln-Ser-Glu-Leu) has an affinity for 
Pex $5 \mathrm{p}$ two orders of magnitude lower than that of the wild-type PTS1 peptide (Tyr-Gln-Ser-Lys-Leu) ${ }^{6}$. Consequently, both hydrophobic and hydrophilic key residues in PTS1 and PTS2 achieve their specific complementarity with the receptors.

Our crystal structure supports several ideas presented in a recent modeling and mutational study of the human Pex7p-PTS2 complex ${ }^{25}$. That study proposed that PTS2 forms an amphipathic $\alpha$-helix and binds to the top surface of Pex $7 p$, and that the hydrophilic key residues of PTS2 (Arg4 and His11 in S. cerevisiae Fox3p) interact with two glutamates in Pex7p (Glu106 and Glu222 in S. cerevisiae Pex7p). However, because their model did not contain a co-receptor peroxin, the bound surface of the modeled PTS2 helix is tilted compared with the crystal structure. In the crystal structure, Fox3p Arg4 interacts with Pex7p Asp61 in addition to Glu106, and Fox3p His11 mainly interacts with Pex7p Tyr178 and Tyr304 in addition to Glu222. This explains the previous finding that Arg substitution of Glu222 (Glu200 in human Pex $7 p$ ) did not destroy the interaction completely, and that the corresponding mutant still partially complemented Pex $7 \mathrm{p}$ deficiency ${ }^{25}$.

The first reported structure of the PTS2-recognition complex, presented here, provides a structural framework for studying the import of PTS2-cargo into peroxisomes. Together with previous reports of the PTS1 system, these findings deepen our understanding of peroxisomal 
protein transport and reveal differences between peroxisomal targeting signals and those that target proteins to other organelles. However, additional structures of PTS2-recognition complexes containing other PTS2 sequences or containing Pex7p and the co-receptor peroxin from other species will be required for a full understanding of the interactions among PTS2, Pex7p, and the co-receptor peroxin. 
Accession codes. Protein Data Bank: Coordinates and structure factors have been deposited with accession code $3 \mathrm{~W} 15$.

\section{ACKNOWLEDGEMENTS}

We thank H. Hirai for helpful advices on plasmid construction, protein purification, and crystallization. We thank Y. Matsuura for critical reading of the manuscript. This work was supported by the Targeted Proteins Research Program of MEXT, Japan (H.K.).

\section{AUTHOR CONTRIBUTIONS}

D.P. generated plasmids, proteins, and crystals. D.P. and T.N. collected diffraction data and solved the structure. D.P. performed pull-down experiments and in vivo functional assays. H.K. supervised the project. D.P. and H.K. wrote the paper. 


\section{References for main text}

1. Wanders, R.J. \& Waterham, H.R. Biochemistry of mammalian peroxisomes revisited. Annu. Rev. Biochem. 75, 295-332 (2006).

2. Platta, H.W. \& Erdmann, R. Peroxisomal dynamics. Trends Cell Biol. 17, 474-484 (2007).

3. Ma, C., Agrawal, G. \& Subramani, S. Peroxisome assembly: matrix and membrane protein biogenesis. J. Cell Biol. 193, 7-16 (2011).

4. Steinberg, S.J. et al. Peroxisome biogenesis disorders. Biochim. Biophys. Acta 1763, 1733-1748 (2006).

5. Stanley, W.A. et al. Recognition of a functional peroxisome type 1 target by the dynamic import receptor pex5p. Mol. Cell 24, 653-663 (2006).

6. Gatto, G.J., Jr., Geisbrecht, B.V., Gould, S.J. \& Berg, J.M. Peroxisomal targeting signal-1 recognition by the TPR domains of human PEX5. Nat. Struct. Biol. 7, 1091-1095 (2000).

7. Lazarow, P.B. The import receptor Pex $7 \mathrm{p}$ and the PTS2 targeting sequence. Biochim. Biophys. Acta 1763, 1599-1604 (2006).

8. Schliebs, W. \& Kunau, W.H. PTS2 co-receptors: diverse proteins with common features. Biochim. Biophys. Acta 1763, 1605-1612 (2006).

9. Swinkels, B.W., Gould, S.J., Bodnar, A.G., Rachubinski, R.A. \& Subramani, S. A novel, cleavable peroxisomal targeting signal at the amino-terminus of the rat 3-ketoacyl-CoA thiolase. EMBO J. 10, 3255-3262 (1991).

10. Osumi, T. et al. Amino-terminal presequence of the precursor of peroxisomal 3-ketoacyl-CoA thiolase is a cleavable signal peptide for peroxisomal targeting. Biochem. Biophys. Res. Commun. 181, 947-954 (1991).

11. Petriv, O.I., Tang, L., Titorenko, V.I. \& Rachubinski, R.A. A new definition for the consensus sequence of the peroxisome targeting signal type 2. J. Mol. Biol. 341, 119-134 (2004).

12. Marzioch, M., Erdmann, R., Veenhuis, M. \& Kunau, W.H. PAS7 encodes a novel yeast member of the WD-40 protein family essential for import of 3-oxoacyl-CoA thiolase, a PTS2-containing protein, into peroxisomes. EMBO J. 13, 4908-4918 (1994).

13. Zhang, J.W. \& Lazarow, P.B. PEB1 (PAS7) in Saccharomyces cerevisiae encodes a hydrophilic, intra-peroxisomal protein that is a member of the WD repeat family and is essential for the import of thiolase into peroxisomes. J. Cell Biol. 129, 65-80 (1995). 
14. Braverman, N. et al. Human PEX7 encodes the peroxisomal PTS2 receptor and is responsible for rhizomelic chondrodysplasia punctata. Nat. Genet. 15, 369-376 (1997).

15. Motley, A.M. et al. Rhizomelic chondrodysplasia punctata is a peroxisomal protein targeting disease caused by a non-functional PTS2 receptor. Nat. Genet. 15, 377-380 (1997).

16. Purdue, P.E., Zhang, J.W., Skoneczny, M. \& Lazarow, P.B. Rhizomelic chondrodysplasia punctata is caused by deficiency of human PEX7, a homologue of the yeast PTS2 receptor. Nat. Genet. 15, 381-384 (1997).

17. Elgersma, Y. et al. A mobile PTS2 receptor for peroxisomal protein import in Pichia pastoris. J. Cell Biol. 140, 807-820 (1998).

18. Mukai, S., Ghaedi, K. \& Fujiki, Y. Intracellular localization, function, and dysfunction of the peroxisome-targeting signal type 2 receptor, Pex7p, in mammalian cells. J. Biol. Chem. 277, 9548-9561 (2002).

19. Nito, K., Hayashi, M. \& Nishimura, M. Direct interaction and determination of binding domains among peroxisomal import factors in Arabidopsis thaliana. Plant Cell Physiol. 43, 355-366 (2002).

20. Sichting, M., Schell-Steven, A., Prokisch, H., Erdmann, R. \& Rottensteiner, H. Pex 7p and Pex20p of Neurospora crassa function together in PTS2-dependent protein import into peroxisomes. Mol. Biol. Cell 14, 810-821 (2003).

21. Rehling, P. et al. The import receptor for the peroxisomal targeting signal 2 (PTS2) in Saccharomyces cerevisiae is encoded by the PAS7 gene. EMBO J. 15, 2901-2913 (1996).

22. Glover, J.R., Andrews, D.W., Subramani, S. \& Rachubinski, R.A. Mutagenesis of the amino targeting signal of Saccharomyces cerevisiae 3-ketoacyl-CoA thiolase reveals conserved amino acids required for import into peroxisomes in vivo. J. Biol. Chem. 269, 7558--7563 (1994).

23. Braverman, N. et al. Mutation analysis of PEX7 in 60 probands with rhizomelic chondrodysplasia punctata and functional correlations of genotype with phenotype. Hum. Mutat. 20, 284-297 (2002).

24. Motley, A.M. et al. Mutational spectrum in the PEX7 gene and functional analysis of mutant alleles in 78 patients with rhizomelic chondrodysplasia punctata type 1. Am. J. Hum. Genet. 70, 612-624 (2002).

25. Kunze, M. et al. Structural requirements for interaction of peroxisomal targeting signal 2 and its receptor PEX7. J. Biol. Chem. 286, 45048-45062 (2011).

26. Purdue, P.E., Yang, X. \& Lazarow, P.B. Pex18p and Pex21p, a novel pair of related 
peroxins essential for peroxisomal targeting by the PTS2 pathway. J. Cell Biol. 143, 1859-1869 (1998).

27. Einwachter, H., Sowinski, S., Kunau, W.H. \& Schliebs, W. Yarrowia lipolytica Pex20p, Saccharomyces cerevisiae Pex18p/Pex21p and mammalian Pex5pL fulfil a common function in the early steps of the peroxisomal PTS2 import pathway. EMBO Rep. 2 , 1035-1039 (2001).

28. Leon, S. et al. Dynamics of the peroxisomal import cycle of PpPex20p: ubiquitin-dependent localization and regulation. J. Cell Biol. 172, 67-78 (2006).

29. Khan, B.R. \& Zolman, B.K. pex5 Mutants that differentially disrupt PTS1 and PTS2 peroxisomal matrix protein import in Arabidopsis. Plant Physiol. 154, 1602-1615 (2010).

30. Braverman, N., Dodt, G., Gould, S.J. \& Valle, D. An isoform of pex5p, the human PTS1 receptor, is required for the import of PTS2 proteins into peroxisomes. Hum. Mol. Genet. 7, 1195-1205 (1998).

31. Otera, H. et al. Peroxisome targeting signal type 1 (PTS1) receptor is involved in import of both PTS1 and PTS2: studies with PEX5-defective CHO cell mutants. Mol. Cell Biol. 18, 388-399 (1998).

32. Matsumura, T., Otera, H. \& Fujiki, Y. Disruption of the interaction of the longer isoform of Pex5p, Pex 5pL, with Pex $7 p$ abolishes peroxisome targeting signal type 2 protein import in mammals. Study with a novel Pex5-impaired Chinese hamster ovary cell mutant. J. Biol. Chem. 275, 21715-21721 (2000).

33. Dodt, G., Warren, D., Becker, E., Rehling, P. \& Gould, S.J. Domain mapping of human PEX5 reveals functional and structural similarities to Saccharomyces cerevisiae Pex18p and Pex21p. J. Biol. Chem. 276, 41769-41781 (2001).

34. Leon, S. \& Subramani, S. A conserved cysteine residue of Pichia pastoris Pex20p is essential for its recycling from the peroxisome to the cytosol. J. Biol. Chem. 282, 7424-7430 (2007).

35. Hensel, A. et al. Cysteine-dependent ubiquitination of Pex18p is linked to cargo translocation across the peroxisomal membrane. J. Biol. Chem. 286, 43495-43505 (2011).

36. Neufeld, C. et al. Structural basis for competitive interactions of Pex14 with the import receptors Pex5 and Pex19. EMBO J. 28, 745-754 (2009).

37. Smith, T.F., Gaitatzes, C., Saxena, K. \& Neer, E.J. The WD repeat: a common architecture for diverse functions. Trends Biochem. Sci. 24, 181-185 (1999).

38. Wall, M.A. et al. The structure of the G protein heterotrimer Gi alpha 1 beta 1 gamma 2 . 
Cell 83, 1047-1058 (1995).

39. Couture, J.F., Collazo, E. \& Trievel, R.C. Molecular recognition of histone H3 by the WD40 protein WDR5. Nat. Struct. Mol. Biol. 13, 698-703 (2006).

40. Janda, C.Y. et al. Recognition of a signal peptide by the signal recognition particle. Nature 465, 507-510 (2010).

41. Abe, Y. et al. Structural basis of presequence recognition by the mitochondrial protein import receptor Tom20. Cell 100, 551-560 (2000).

42. Baker, N.A., Sept, D., Joseph, S., Holst, M.J. \& McCammon, J.A. Electrostatics of nanosystems: application to microtubules and the ribosome. Proc. Natl. Acad. Sci. USA 98, 10037-10041 (2001). 


\section{Figure legends}

\section{Figure 1}

Structure of the Pex7p-Pex21pC-Fox3pN-MBP complex. (a) Schematic diagrams of the constructs used for crystallization. The color code here is used for all figures, unless otherwise noted. WD1-6 indicate WD40 motifs. ND, N-terminal conserved domain; WF, Wxxx[F/Y] Pex14p-binding motif; Pex7pBD, Pex7p-binding domain. (b) Skeleton representation of the hetero-trimer in the crystallographic asymmetric unit. (c) Ribbon and surface representations of the side view (left) and the top view (right) of the hetero-trimer Pex7p-Pex21pC-Fox3pN. Side chains of Arg4, Leu5, His11, and Leu12 are shown as stick models. The disordered loops (DLs) in Pex7p and Pex21pC are presented as dashed curves. The red arrow in the leftmost panel represents the viewpoint of the left panel in Fig. $3 \mathrm{~b}$ and the viewpoint of Fig. 4c. Nt, N-terminus; Ct, C-terminus.

\section{Figure 2}

Cooperative complex formation of Fox $3 p, \operatorname{Pex} 7 \mathrm{p}$, and Pex $21 \mathrm{pC}$. The results of pull-down experiments using glutathione sepharose resin (a) or amylose resin (b) to examine all combinations of complex formation between any two or all three of Fox $3 p$, Pex $7 p$, and 
Pex $21 \mathrm{pC}$ are shown. Proteins were mixed at $5 \mu \mathrm{M}$ with $15 \mu \mathrm{l}$ of resin in buffer. The input and bound fractions were analyzed by SDS-PAGE and stained with Coomassie Brilliant Blue.

\section{Figure 3}

Pex $7 \mathrm{p}-\mathrm{Pex} 21 \mathrm{pC}$ receptor complex formation. (a) Open-book representation of Pex $7 \mathrm{p}$ and Pex21pC. Pex7p is in the same orientation as in the right panel of Fig. 1c. Pex21pC is in the orientation rotated by $135^{\circ}$ from the orientation in the right panel of Fig. 1c. Fox $3 \mathrm{pN}$ is shown as a ribbon model in yellow, and the side-chains of Met1, Arg4, Leu5, Ile8, His11, and Leu12 are shown to indicate its orientation. Electrostatic surfaces of Pex $7 \mathrm{p}$ and Pex $21 \mathrm{pC}$ were colored according to local surface properties using PyMOL with the APBS ${ }^{42}$ plugin. Surface regions of positive potential are colored blue, regions of negative potential red, and neutral regions white. The color ramp is from $-3 k T$ to $+3 k T$, where $k$ is the Boltzmann constant and $T$ is the absolute temperature. The dashed boxes indicate the hydrophobic interfaces important for Pex $7 p-P e x 21 p$ complex formation. In particular, the dashed box on Pex $7 p$ indicates the hydrophobic ridge. The dashed circle indicates the bulge loop. (b) Residues forming hydrophobic interfaces between Pex $7 \mathrm{p}$ and Pex $21 \mathrm{pC}$ are shown in the left panel, and residues forming electrostatic interactions between Pex $7 \mathrm{p}$ and Pex $21 \mathrm{pC}$ in the right panel. The 
viewpoint of the left panel is indicated in Fig. 1c by a red arrow, and the helix of Fox3pN is omitted from the left panel for clarity. Dashed black lines indicate possible hydrogen bonds.

\section{Figure 4}

Molecular recognition of key residues of PTS2. (a) The amphipathic $\alpha$-helix of Fox3pN. Hydrophobic residues are highlighted by underlines. (b) Stereo view of the PTS2 binding pocket. The side chains of Met1, Arg4, Leu5, Ile8, His11, and Leu12 of Fox3pN are shown. Dashed black lines indicate possible hydrogen bonds. (c) The surface of the PTS2-binding pocket is shown and colored according to the peptide chain (Pex21pC, light pink; Pex7p, pale green) in the left panel, and colored according to local electrostatic properties as in Fig. 3a in the right panel. The viewpoint is indicated in Fig. 1 $\mathrm{c}$ by a red arrow. The dashed box indicates the hydrophobic groove, and the dashed ellipse indicates the hydrophilic groove.

\section{Figure 5}

Functional assays of Pex7p and Pex21p variants. $(a, b)$ The results of pull-down experiments with amylose resin to examine the ability of variants of Pex21pC (a) and Pex7p (b) to form the ternary complex. (c) Growth assays of the $S$. cerevisiae strains on SCOT agar plates (oleic acid 
is the only carbon source) or SCDT agar plates (glucose is the only carbon source). Ten-fold serial dilutions of the strains were spotted onto the agar plates and incubated at $30^{\circ} \mathrm{C}$ for one week (SCOT) or one day (SCDT). Approximate numbers of cells per spot are indicated. WT, wild type. 
Table 1. Data collection and refinement statistics

\begin{tabular}{|c|c|}
\hline & $\operatorname{Pex} 7 \mathrm{p}(\Delta 257-265)-\mathrm{Pex} 21 \mathrm{pC}-\mathrm{Fox} 3 \mathrm{pN}-\mathrm{MBP}$ \\
\hline \multicolumn{2}{|l|}{ Data collection } \\
\hline Space group & $P 2_{1}$ \\
\hline \multicolumn{2}{|l|}{ Cell dimensions } \\
\hline$a, b, c(\AA)$ & $78.9,52.8,97.6$ \\
\hline$\alpha, \beta, \gamma\left({ }^{\circ}\right)$ & $90,106.6,90$ \\
\hline Resolution $(\AA)$ & $32.2-1.8(1.90-1.80)^{*}$ \\
\hline$R_{\text {merge }}$ & $0.066(0.199)$ \\
\hline$I / \sigma I$ & $20.2(8.8)$ \\
\hline Completeness (\%) & $99.8(99.2)$ \\
\hline Redundancy & $7.1(6.9)$ \\
\hline \multicolumn{2}{|l|}{ Refinement } \\
\hline Resolution $(\AA)$ & $32.2-1.80$ \\
\hline No. reflections & 67,828 \\
\hline$R_{\text {work }} / R_{\text {free }}$ & $0.189 / 0.224$ \\
\hline \multicolumn{2}{|l|}{ No. atoms } \\
\hline Protein & 6,219 \\
\hline Ligand/ion & 42 \\
\hline Water & 563 \\
\hline \multicolumn{2}{|l|}{$B$-factors } \\
\hline Protein & 20.87 \\
\hline Ligand/ion & 34.13 \\
\hline Water & 26.45 \\
\hline \multicolumn{2}{|l|}{ r.m.s. deviations } \\
\hline Bond lengths $(\AA)$ & 0.008 \\
\hline Bond angles $\left({ }^{\circ}\right)$ & 1.063 \\
\hline
\end{tabular}

*Values in parentheses are for the highest-resolution shell. 
Online Methods

Plasmids. The details of plasmids used in this study are described in Supplementary Note and Supplementary Table 1.

Expression and purification of Pex7p and its variants. P. pastoris plasmids for expression of N-terminally GST-tagged Pex7p and its variants were linearized with PmeI (NEB) and transformed into $P$. pastoris strain SMD1163 (Invitrogen) as described $^{43}$. Positive transformants were selected using YPD (1\% yeast extract, 2\% peptone, 2\% dextrose) agar plates containing $300 \mu \mathrm{g} \mathrm{ml}^{-1}$ Zeocin. The colonies were grown at $30^{\circ} \mathrm{C}$ to an $\mathrm{OD}_{600}$ of 5 in YPD medium, and $20 \mathrm{ml}$ of this culture was used to inoculate 11 of methanol induction medium ( $1 \%$ methanol, $1 \%$ yeast extract, $1.5 \%$ peptone, $1.34 \%$ yeast nitrogen base with ammonium sulfate without amino acids, $0.5 \%$ sorbitol, $4 \times 10^{-5} \%$ biotin) in $5-1$ baffled flasks. The cells were grown at $30^{\circ} \mathrm{C}$ with vigorous shaking. Methanol was added to a concentration of $0.7 \%$ after 16 $\mathrm{h}$ of induction, and cells were harvested after additional culture for $4 \mathrm{~h}$.

Protein samples were kept at $4^{\circ} \mathrm{C}$ during all subsequent steps. Harvested cells $(90 \mathrm{~g})$ were suspended in $250 \mathrm{ml}$ buffer A (30 mM Tris-HCl pH 7.5, $500 \mathrm{mM} \mathrm{NaCl}, 5 \%$ glycerol, $0.05 \%$ Tween 20, $1 \mathrm{mM}$ DTT, $1 \mathrm{mM}$ PMSF) and lysed with an Emulsiflex-C3 high-pressure 
homogenizer (Avestin). Clarified lysate was incubated with $3 \mathrm{ml}$ Glutathione Sepharose 4B resin (GE Healthcare) overnight. After washing the resin with 50 column volumes (CVs) of buffer B (30 mM Tris-HCl pH 7.5, $300 \mathrm{mM} \mathrm{NaCl}, 1$ mM DTT), His 6 -tagged TEV protease was mixed with the resin and $1 \mathrm{CV}$ of buffer B overnight to remove the GST-tag and release Pex $7 \mathrm{p}$ from the resin. The supernatant was passed through $1 \mathrm{ml} \mathrm{Ni-IMAC} \mathrm{(Bio-Rad)} \mathrm{column} \mathrm{to}$ remove TEV protease, and the unbound fraction containing Pex $7 \mathrm{p}$ was applied to a HiLoad 16/60 Superdex 200 pg gel filtration column (GE Healthcare) equilibrated with buffer B. Peak fractions containing Pex7p were pooled, concentrated with Amicon Ultra Centrifugal Filters (Millipore), flash-frozen in liquid nitrogen, and stored at $-80^{\circ} \mathrm{C}$. The yield of Pex $7 \mathrm{p}$ was $0.4 \mathrm{mg}$ per liter of culture.

Expression and purification of Pex21pC, Fox3p, Fox3pN-MBP, and MBP-Pex21pC. $E$. coli BL21(DE3) cells transformed with plasmids for expression of N-terminally GST-tagged Pex21pC, Fox3p, or Fox3pN-MBP were grown in $\mathrm{LB}$ medium at $37^{\circ} \mathrm{C}$ to an $\mathrm{OD}_{600}$ of 0.6 . Protein expression was induced with $0.5 \mathrm{mM} \mathrm{IPTG}$ for $4 \mathrm{~h}$ at $37^{\circ} \mathrm{C}$. Harvested cells $(10 \mathrm{~g})$ were suspended in $80 \mathrm{ml}$ buffer C (30 mM Tris-HCl pH 7.5, $150 \mathrm{mM} \mathrm{NaCl}, 1 \mathrm{mM}$ DTT) containing $1 \mathrm{mM}$ PMSF and lysed by sonication on ice. Further purification after disruption of the cells 
was performed using the same procedure as for purification of Pex $7 \mathrm{p}$ described above, except that buffer $\mathrm{C}$ was used for washing the resin and gel filtration chromatography. Purified Pex21pC, Fox3p, and Fox3pN-MBP were concentrated in buffer C, flash-frozen, and stored at $-80^{\circ} \mathrm{C}$. The yield of Pex $21 \mathrm{pC}$, Fox $3 \mathrm{p}$, and Fox $3 \mathrm{pN}-\mathrm{MBP}$ were 2,10 , and $>20 \mathrm{mg}$ per liter of culture, respectively.

E. coli BL21(DE3) cells transformed with plasmids for expression of C-terminally His $_{6}$-tagged MBP-Pex21pC and its variants were cultured in the same way as cells expressing GST-tagged Pex21pC. Harvested cells $(1 \mathrm{~g})$ were suspended in $25 \mathrm{ml}$ buffer B and lysed by sonication on ice. Clarified lysate was supplied with imidazole to a concentration of $20 \mathrm{mM}$ and applied on $1 \mathrm{ml} \mathrm{Ni-IMAC} \mathrm{column.} \mathrm{The} \mathrm{resin} \mathrm{was} \mathrm{washed} \mathrm{with} 25 \mathrm{CVs}$ of buffer B containing $20 \mathrm{mM}$ imidazole and MBP-Pex21pC was eluted with buffer B containing $400 \mathrm{mM}$ imidazole. Eluted proteins were concentrated in buffer B, flash frozen and stored at $-80^{\circ} \mathrm{C}$.

Crystallization of $\operatorname{Pex} 7 \mathrm{p}(\Delta 257-265)-P \operatorname{ex21pC-Fox3pN-MBP}$ hetero-trimer. Purified $\operatorname{Pex} 7 \mathrm{p}(\Delta 257-265)(2 \mathrm{mg})$, Pex21pC (1 mg), and Fox3pN-MBP (4 mg) were mixed in $4 \mathrm{ml}$ buffer $\mathrm{B}$, incubated overnight at $4^{\circ} \mathrm{C}$, and subjected to gel filtration chromatography on a HiLoad 16/60 Superdex $200 \mathrm{pg}$ column with buffer C. The peak fractions containing the ternary 
complex were confirmed by SDS-PAGE, and concentrated in buffer C to $14 \mathrm{mg} \mathrm{ml}^{-1}$. Crystals were grown at $20^{\circ} \mathrm{C}$ by hanging-drop vapor diffusion, mixing $1 \mu 1$ of the protein solution and 1 $\mu \mathrm{l}$ of the reservoir solution containing 25\% PEG2000, 0.3 M magnesium nitrate, and $0.1 \mathrm{M}$ Tris- $\mathrm{HCl}(\mathrm{pH} 7.7)$. Plate crystals appeared in a week and reached their maximal size $(0.5 \times 0.2$ $\times 0.02 \mathrm{~mm}$ ) within one month.

Data collection and structure determination. The crystals were serially transferred to cryoprotectant solutions (25-35\% PEG2000, 0.1 M NaCl, 0.3 M magnesium nitrate, 0.1 M Tris- $\mathrm{HCl} \mathrm{pH} 7.5$ ) and soaked in the final solution for $1 \mathrm{~h}$ before flash-freezing in liquid nitrogen. A 1.8-Å resolution dataset was collected from a single crystal at $100 \mathrm{~K}$ at the SPring- 8 beamline BL41XU at a wavelength of $1.0000 \AA$ and processed using the $\mathrm{iMOSFLM}^{44}$ and CCP4 software $^{45}$. Initial phases were solved by molecular replacement with PHASER ${ }^{46}$, using crystal structures of MBP (PDB entry 1OMP) and human WDR5 (PDB entry 2H13) as search models. $\mathrm{ARP} / \mathrm{wARP}^{47}$ was used to build the initial model. Incomplete parts of the model were manually built using $\operatorname{Coot}^{48}$ and refined using REFMAC5 ${ }^{49}$ to $R / R_{\text {free }}$ values of $0.189 / 0.224$ at $1.8 \AA$ resolution. As validated with MolProbity ${ }^{50}, 97.8 \%$ of the residues were in the favored region of the Ramachandran plot, and the rest were in the allowed region. Data collection and refinement 
statistics are summarized in Table 1. All structural figures were generated using PyMOL (http://www.pymol.org). PISA ${ }^{51}$ was used to analyze intermolecular interactions and to calculate the surface areas.

GST- and MBP-pull-down experiments. Proteins were diluted to $5 \mu \mathrm{M}$ each in $100 \mu 1$ of buffer B containing $0.01 \%$ Tween 20 . Four-fifths of the mixture was incubated with $15 \mu 1$ of Glutathione Sepharose 4B resin or amylose resin (NEB) at $4^{\circ} \mathrm{C}$ for $1 \mathrm{~h}$, and the remaining $20 \mu \mathrm{l}$ was kept as the input fraction and mixed with $5 \mu 1$ of $5 \times$ sample buffer. The resin was washed three times with $500 \mu \mathrm{l}$ buffer B containing $0.01 \%$ Tween 20 , and the bound fraction was eluted by mixing the resin with $30 \mu 12 \times$ sample buffer. The input fraction and the bound fractions were analyzed by SDS-PAGE and stained with Coomassie Brilliant Blue.

S. cerevisiae strains and complementation assays. All S. cerevisiae strains used in this study were generated from strain BY20134 (W303-1A background), which was provided by the National Bio-Resource Project (NBRP) of the MEXT, Japan. Gene deletion was performed using the one-step PCR method as described ${ }^{52}$. PEX7 was replaced with the URA3 gene to generate strain $\triangle p e x 7$. PEX 21 and PEX18 were replaced serially with the LEU2 and HIS3 genes, 
respectively, to generate strain $\Delta p \operatorname{ex} 184 p \operatorname{ex} 21$. All deletions were confirmed by colony PCR on genomic DNA. Plasmids were transformed into BY20134, Apex7, and Apex184pex21 strains as described $^{53}$, and transformants were selected on SCD $(0.67 \%$ yeast nitrogen base with ammonium sulfate without amino acids, $2 \%$ dextrose supplemented with amino acids, adenine, and uracil) agar plates lacking the appropriate amino acids and/or uracil. BY20134 strain transformed with pAG304-Fox3pN-EGFP/mCherry-PTS1 is referred as BY20134EM. The list of all S. cerevisiae strains used in this study is presented on Supplementary Table 2.

Growth assays of $S$. cerevisiae strains were performed as described previously ${ }^{26}$ with minor modifications. The cells of each strain were grown at $30^{\circ} \mathrm{C}$ to an $\mathrm{OD}_{600}$ of 2 in SCEO medium $(0.67 \%$ yeast nitrogen base with ammonium sulfate without amino acids, $2 \%(\mathrm{v} / \mathrm{v})$ ethanol, $0.1 \%(\mathrm{w} / \mathrm{v})$ oleic acid, $0.4 \%(\mathrm{w} / \mathrm{v})$ Tween 40, appropriate amino acids, uracil, and adenine). The cells were washed with distilled water and applied at ten-fold serial dilutions to SCOT $(0.67 \%$ yeast nitrogen base with ammonium sulfate without amino acids, $0.1 \%(\mathrm{w} / \mathrm{v})$ oleic acid, $0.4 \%(\mathrm{w} / \mathrm{v})$ Tween 40 , amino acids, uracil, and adenine) and SCDT $(0.67 \%$ yeast nitrogen base with ammonium sulfate without amino acids, $2 \%$ dextrose, $0.4 \%(\mathrm{w} / \mathrm{v})$ Tween 40 , amino acids, uracil, and adenine) agar plates and incubated at $30^{\circ} \mathrm{C}$. Aliquots of the cells were also used for western blotting (Supplementary Fig. 5b and Supplementary Note) and 
visualization on a confocal fluorescence microscope (A1, Nikon). 


\section{References for Online Methods}

43. Wu, S. \& Letchworth, G.J. High efficiency transformation by electroporation of Pichia pastoris pretreated with lithium acetate and dithiothreitol. Biotechniques 36, 152-154 (2004).

44. Battye, T.G., Kontogiannis, L., Johnson, O., Powell, H.R. \& Leslie, A.G. iMOSFLM: a new graphical interface for diffraction-image processing with MOSFLM. Acta Crystallogr. D Biol. Crystallogr. 67, 271-281 (2011).

45. Winn, M.D. et al. Overview of the CCP4 suite and current developments. Acta Crystallogr. D Biol. Crystallogr. 67, 235-242 (2011).

46. McCoy, A.J. et al. Phaser crystallographic software. J. Appl. Crystallogr. 40, 658-674 (2007).

47. Perrakis, A., Morris, R. \& Lamzin, V.S. Automated protein model building combined with iterative structure refinement. Nat. Struct. Biol. 6, 458-463 (1999).

48. Emsley, P. \& Cowtan, K. Coot: model-building tools for molecular graphics. Acta Crystallogr. D Biol. Crystallogr. 60, 2126-2132 (2004).

49. Murshudov, G.N., Vagin, A.A. \& Dodson, E.J. Refinement of macromolecular structures by the maximum-likelihood method. Acta Crystallogr. D Biol. Crystallogr. 53, 240-255 (1997).

50. Chen, V.B. et al. MolProbity: all-atom structure validation for macromolecular crystallography. Acta Crystallogr. D Biol. Crystallogr. 66, 12-21 (2010).

51. Krissinel, E. \& Henrick, K. Inference of macromolecular assemblies from crystalline state. J. Mol. Biol. 372, 774-797 (2007).

52. Baudin, A., Ozier-Kalogeropoulos, O., Denouel, A., Lacroute, F. \& Cullin, C. A simple and efficient method for direct gene deletion in Saccharomyces cerevisiae. Nucleic Acids Res. 21, 3329-3330 (1993).

53. Gietz, R.D. \& Schiestl, R.H. Frozen competent yeast cells that can be transformed with high efficiency using the LiAc/SS carrier DNA/PEG method. Nat. Protoc. 2, 1-4 (2007). 
a

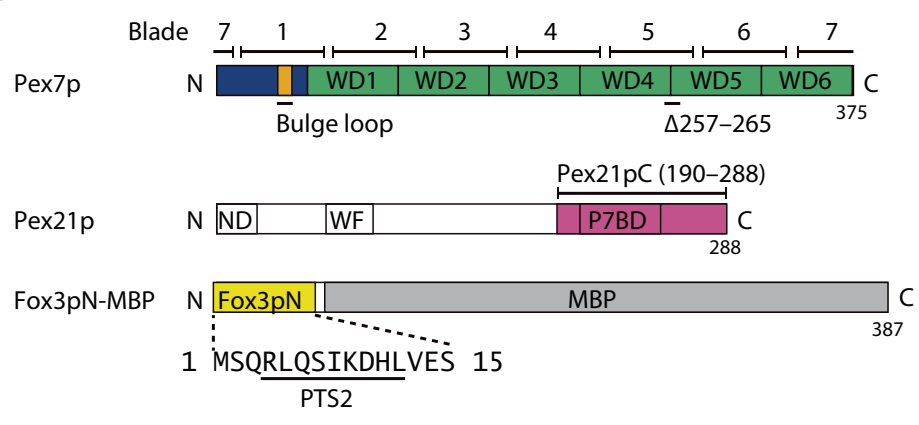

b

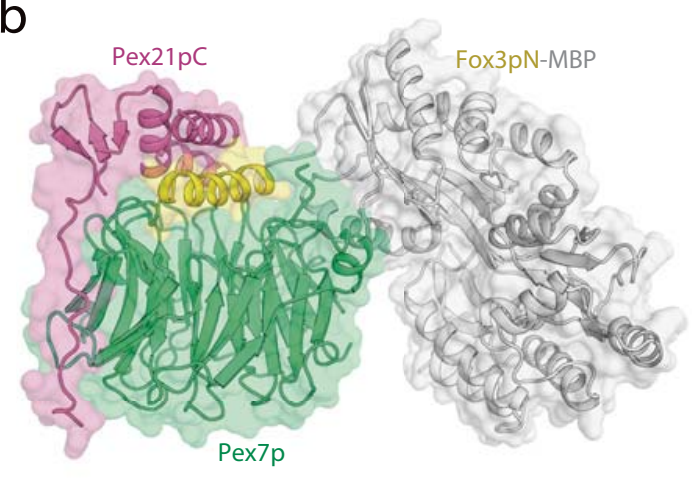

C
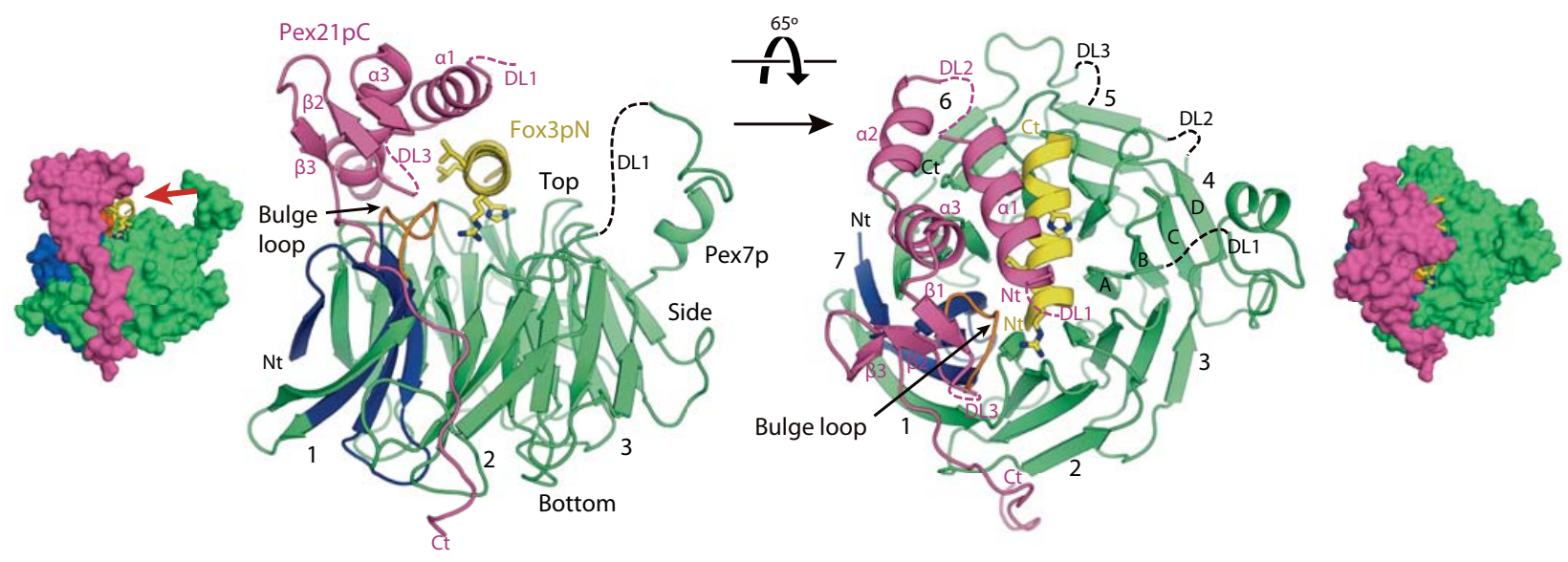

Figure-1, Kato 


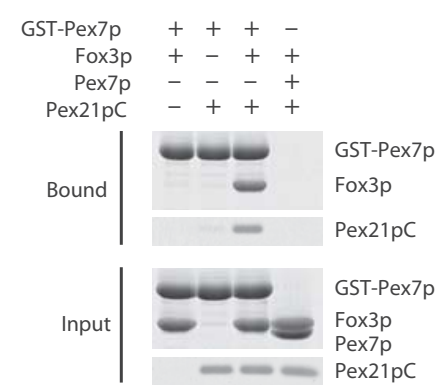

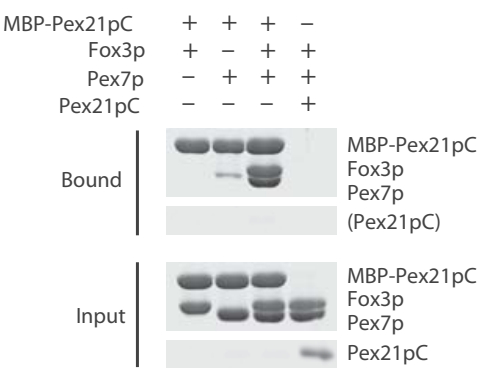

Figure-2, Kato 
a
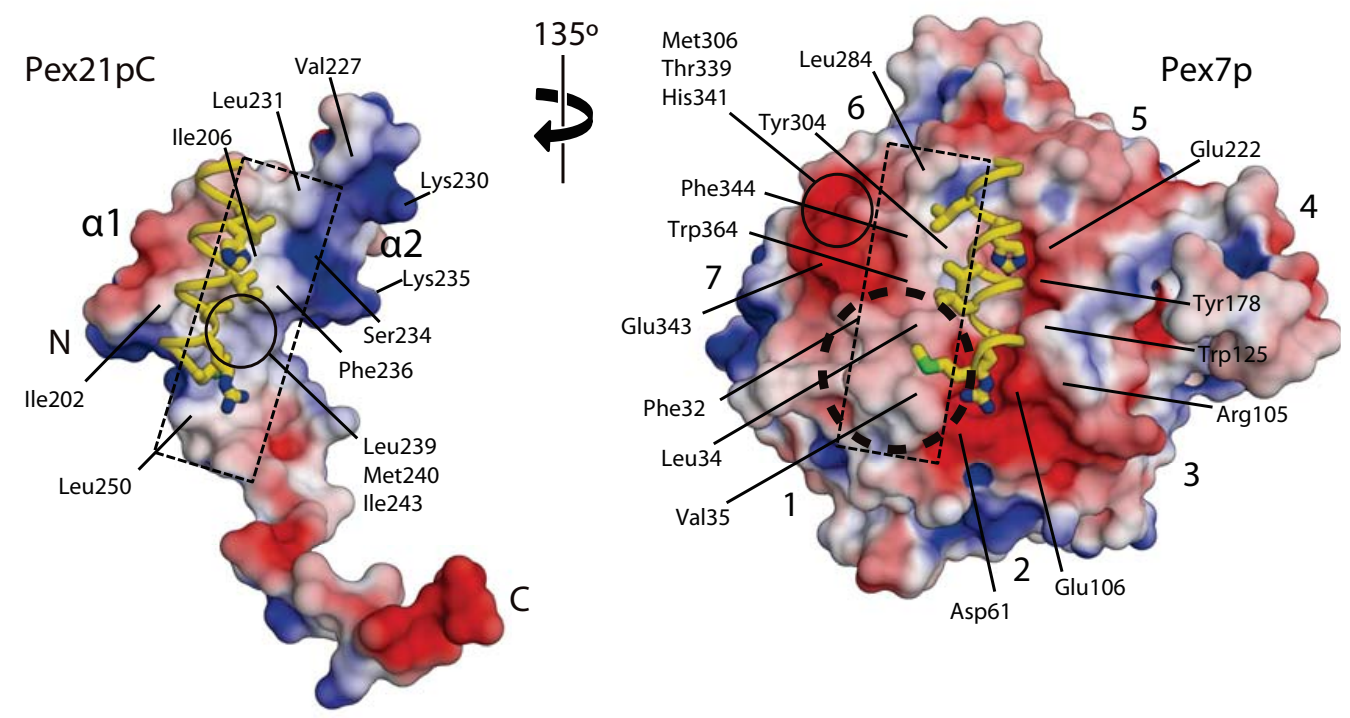

b
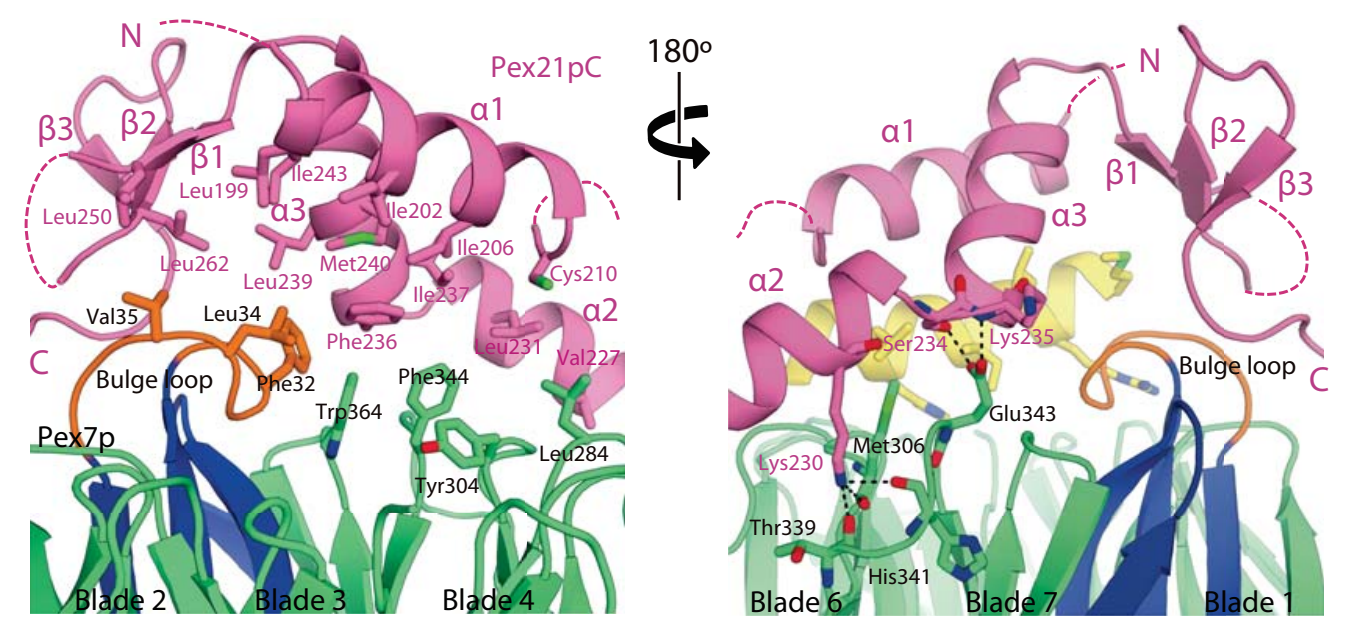

Figure-3, Kato 
a

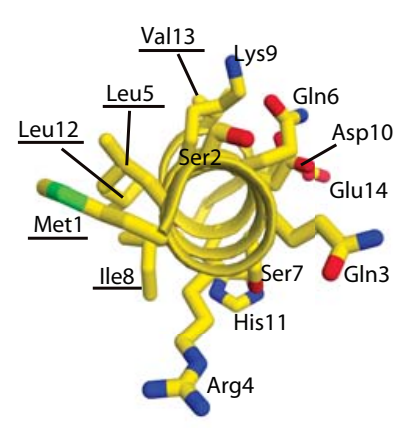

b

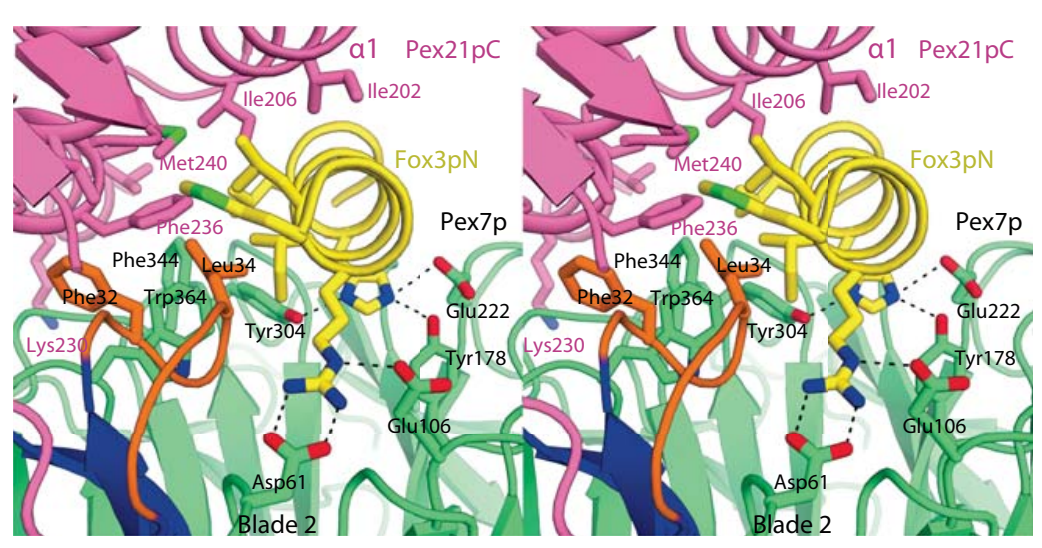

C

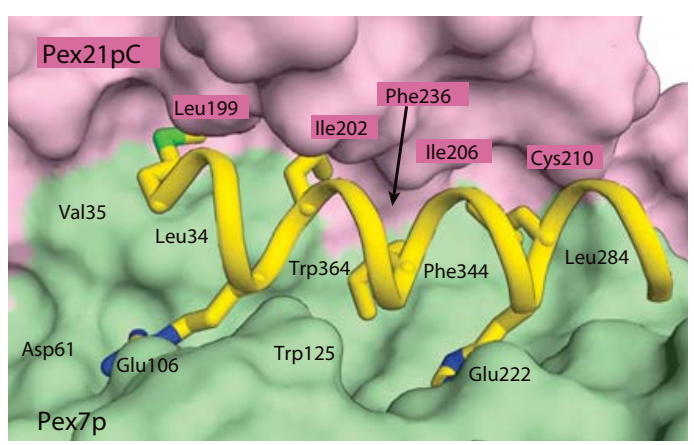

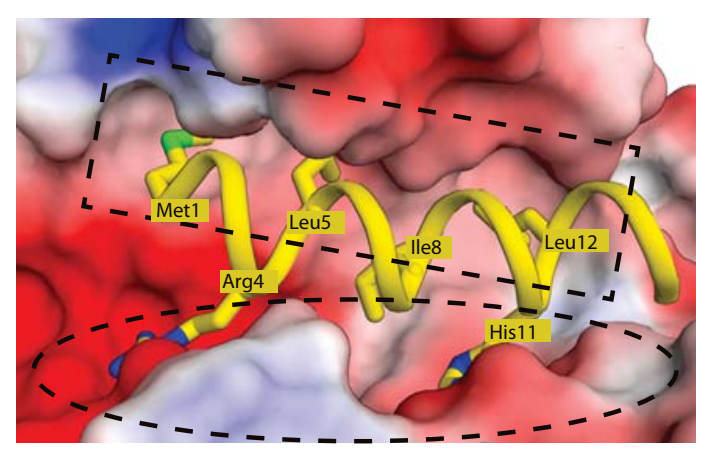

Figure-4, Kato 
a

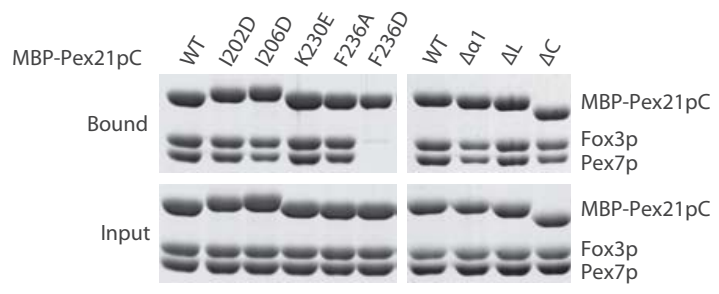

C

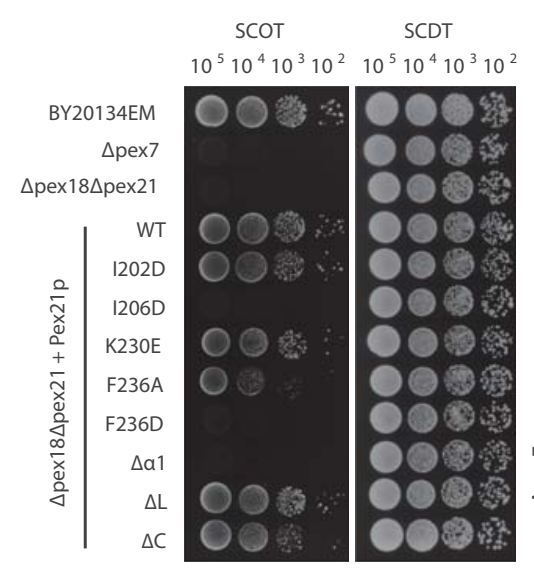

b
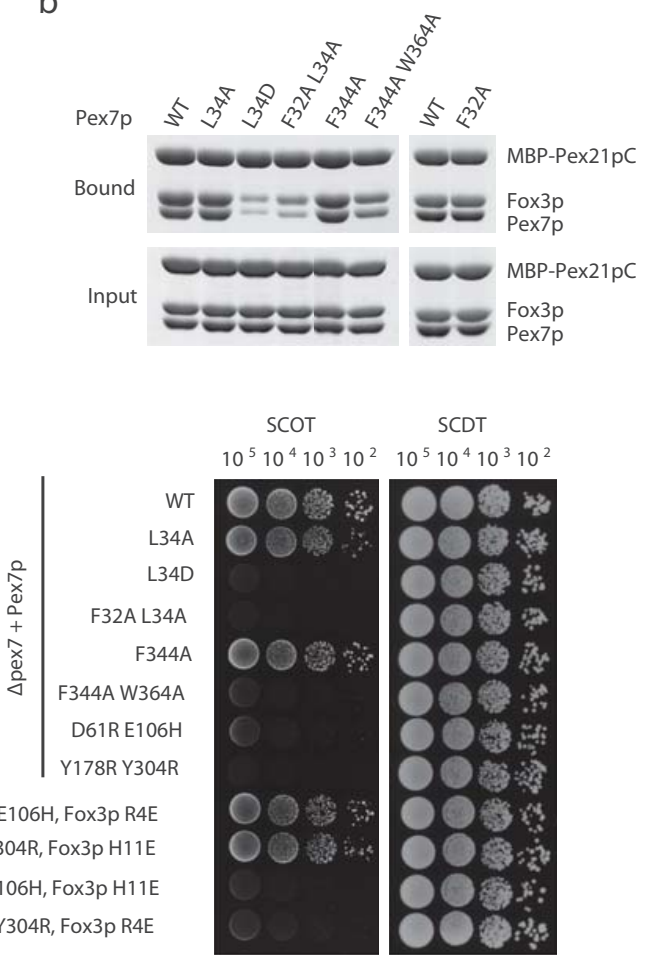

Figure-5, Kato 


\section{Supplementary Figure 1}

Amino acid sequence alignments and conserved residues.

a

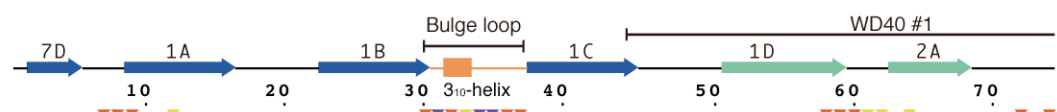

SCPex7p MLRYHMOGFSGYGVQYSPFFDRLAVAAGSFGLVGNGKLFILEIDRSG-RIVEVNSFLTODCLFDLAWNESHEN IAVATSANYGLVGNGRLYVLSIMDDG-NITTDISYDTADAVYDVCWSESHD

AtPex7p
DdPex7p

$X+P$ ex $7 p$
HsPex7p MAVSGDGRILAVRTPDRHGYAVEFSPYKPSTLACATSONYGI SGCGTLVVLEOSEGG - GAVRSFDWT GLYDCTW E TE MAVSGDGRLHAVR IPDRHGYAVEF SPYKPSTLACATSQNYGISGCGTLVVLEQSEGG - IAVRRSFDWTDALFDVTWSE ISEN
MSAVCGGARMLRTPGRGYAAEF SPYPGRLACATAQHY IAGCGTLLILPDEA - - LRLFRSFDWNDGLFDVTWENNEH

\begin{tabular}{|c|c|c|c|c|c|c|}
\hline & & & WD40 & & & \\
\hline $2 B$ & $2 C$ & $2 \mathrm{D}$ & $3 \mathrm{~A}$ & $3 B$ & $3 C$ & $3 \mathrm{D}$ \\
\hline 80 & 90 & 100 & 110 & 120 & 130 & 140 \\
\hline
\end{tabular}

SCPEX7P QVLVAQGDGTLRLFDTFK - -EFPIAIFKEHEREVFSCNWNLVNRQ-NFLSSSWDGSIKIWSPLRKQ- - SLMTLTPR - - - - PPPEXP HVLTSSGDGCVSLFDTTLK--DYPVMKFTEHQREVF SVDWSNIDKN-LFCSASWDGSVKVWSPGSNRNTSLLTLRSLASREEK

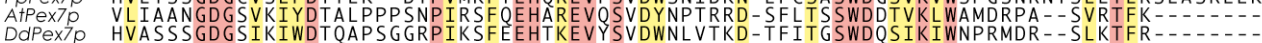

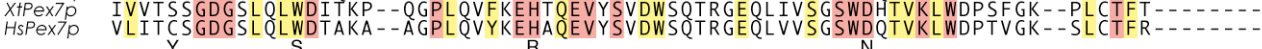

\begin{tabular}{c} 
WD40\#3 \\
\hline 150
\end{tabular}

SCPEX7P
T-PLEITKMVDPLNAII LKKKSF-TGISKNRNCVYQAQF SPHDQNLVLSCSGNSYASLFDIRLPSGKNQNNFL VHSGLEALT

PPPeX7P TGRIEKPIPVVQPSQVP--MSKTRPNIRNDNNDCVYDAKFSFHDPNI IMSCNSDSHLQLWDTRLPNPL - FMDFVAHNGLEALS

AdPex7p HSPex7p

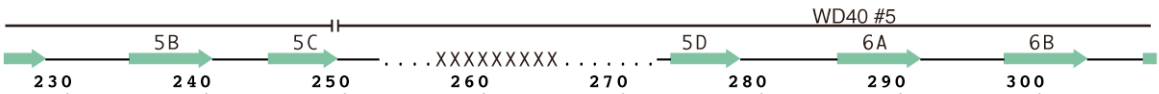

SCPEX7P CDFNKYRPYVVATGGVDNAIRIWDIRMLNKNESATIKRTVPGQLHNSSCINEIPNAHGLAIRKVTWSPHHSNILMSASYDMTC

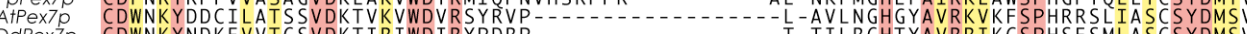

DIPEX7P CDWNKYNDKEVVTGSVDKTIRIWDIRYPDRP-1

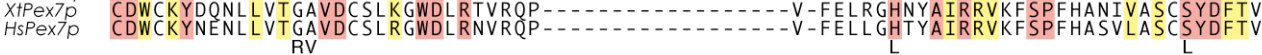

\begin{tabular}{|c|c|c|c|c|c|c|}
\hline $6 \mathrm{CC}$ & & & & $7 \mathrm{~A}$ & $7 B$ & $7 C$ \\
\hline 10 & 320 & 330 & 340 & 350 & 360 & 370 \\
\hline
\end{tabular}

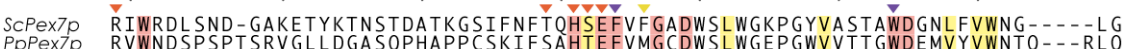

ATPEXTD CLWDYMVE-DALV--

DAPEX7P IVWDRAREQDPII-................

$\begin{array}{ll}\text { XtPeX7P } & \text { RLWDFSKS-SSLL } \\ \text { HSPEXTP } & \text { RFWNFSKP-DSLL-.-. }\end{array}$

b

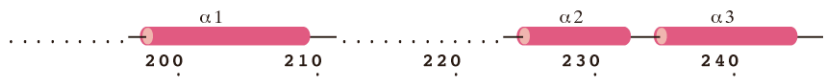

SCPex21P_190-288

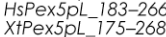

YIPex20p_247-336

NcPex20p_310-406

SCPex18P_192-283
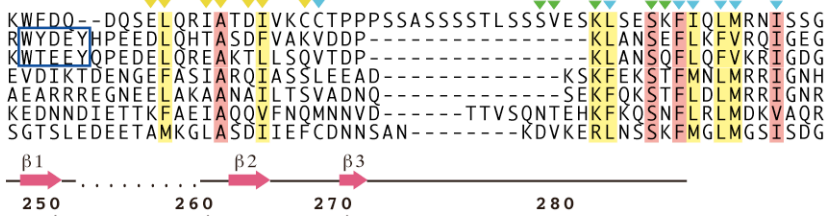

SCPex210_190-288

XIPex5

YIPex20p 247-336

NCPex20p_310-406

PpPex20p_239-323
ScPex18p_192-283

DVTLKKNADGN-SASELFSSNNGELVGNR-- - - HIFVKDEIHKDILD---

QVSLESGAGS--GRAQAE QWAAE FIQQQ---_-GTSDAWVDQFTRPVN

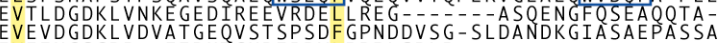

EVEINGSGDR - - F IDKT GNDIRDYLPDPLSDLR--

C
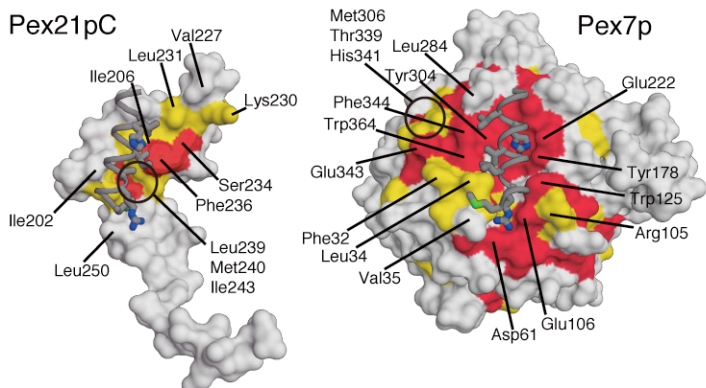
Sequence alignments of (a) six Pex7p homologs, and (b) the homologous regions of co-receptor peroxins for PTS2 and Pex7p binding. Sc, Saccharomyces cerevisiae; Pp, Pichia pastoris; At, Arabidopsis thaliana; Dd, Dictyostelium discoideum; Xt, Xenopus tropicalis; Hs, Homo sapiens; YI, Yarrowia lipolytica; Nc, Neurospora crassa. Alignments were performed with ClustalW $1.83^{1}$ and manually adjusted. Residues that are identical in all sequences are shaded red, and residues that only have conserved substitutions are shaded yellow. Secondary-structure elements and residue numbering of Pex7p and Pex21pC are indicated above the alignments. Point mutations of human Pex7p that cause RCDP1 $1^{2,3}$ are indicated below the sequence of HsPex7p. In (a, b), "." indicates a residue missing electron density; " $X$ " indicates a residue deleted to optimize crystal quality. Down-pointing triangles indicate the interface residues, and are colored as follows: residues of Pex7p and Pex21p that only interact with Fox3pN are yellow; residues of Pex7p that interact with Pex21p are red; residues of Pex7p that interact with both Fox3pN and Pex21p are purple; residues of Pex21p that interact with Pex7p are green; and residues of Pex21p that interact with both Fox3pN and Pex7p are cyan. Blue-boxed regions in (b) indicate the Pex14p-binding motif. (c) Surface representation of Pex21pC and Pex7p. The surfaces of conserved residues are highlighted as in $(a, b)$ according to their conservation. 


\section{Supplementary Figure 2}

Fox3p binds to Pex7p with higher affinity in the lower salt environment.

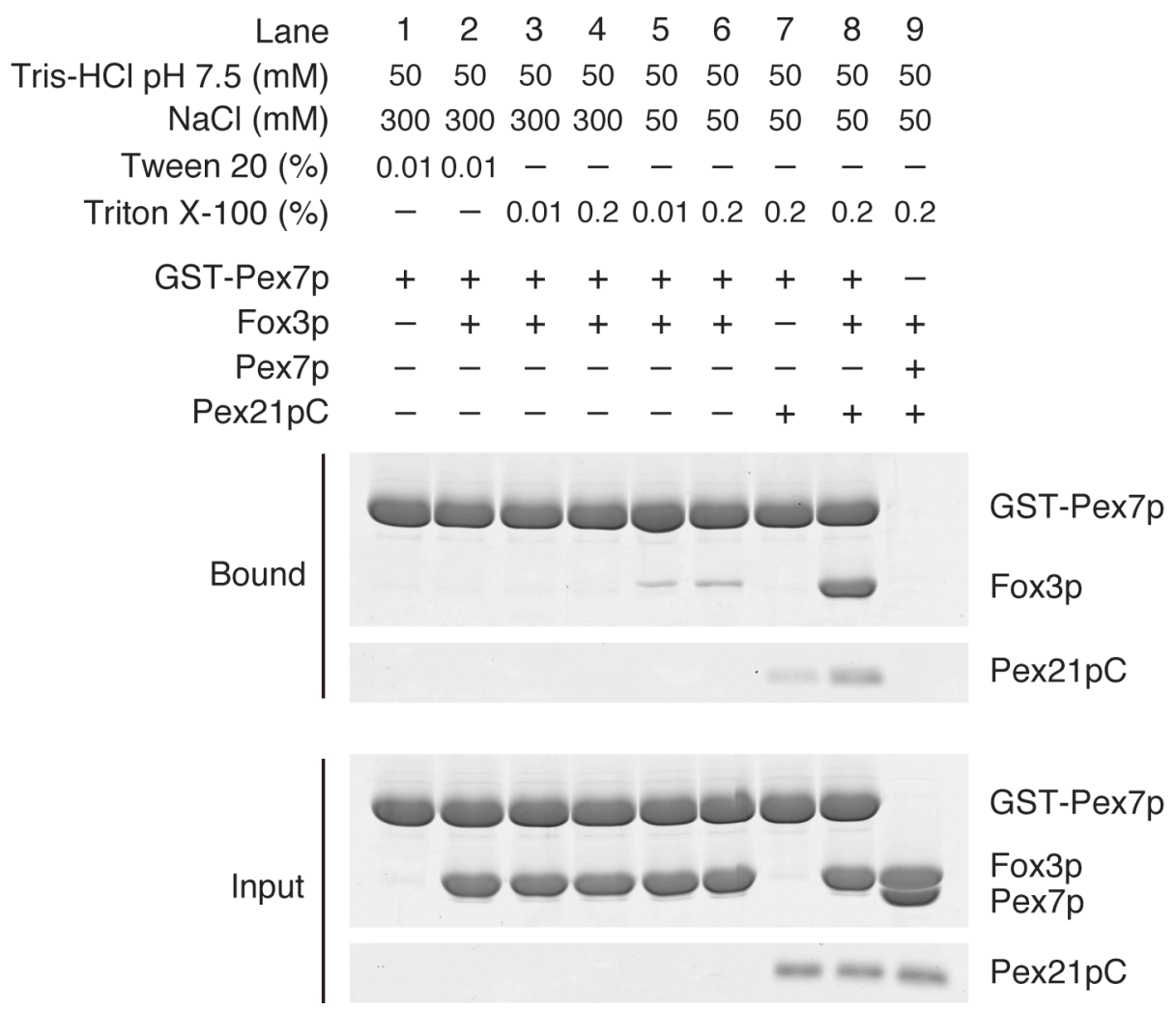

Pull-down experiments were performed using glutathione sepharose resin under the procedure described in the Online Methods section. Proteins were diluted to $5 \mu \mathrm{M}$ in buffers containing $50 \mathrm{mM}$ Tris- $\mathrm{HCl} \mathrm{pH} 7.5$ and different concentrations of $\mathrm{NaCl}$, Tween 20 , and Triton $X-100$ indicated in the figure. The input and bound fractions were analyzed by SDS-PAGE and stained with Coomassie Brilliant Blue. The buffer composition for the experiment of lane 6 was based on the solution A described previously 4 


\section{Supplementary Figure 3}

Electron-density maps around the PTS2-recognition site.

a

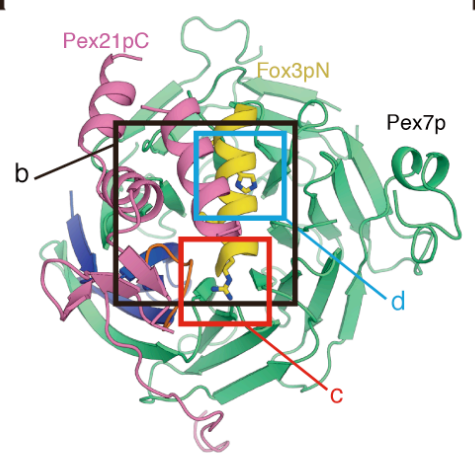

C

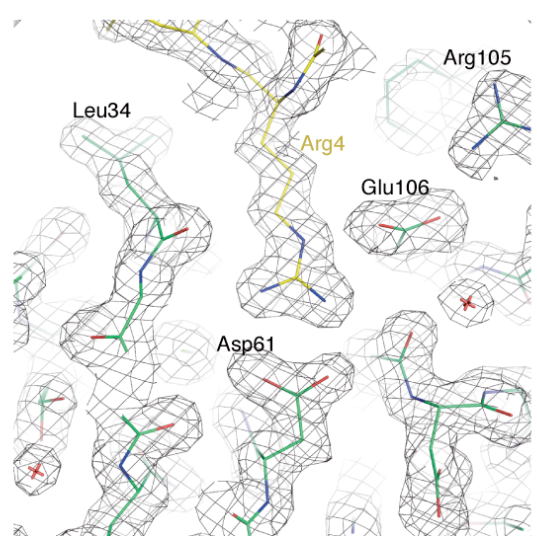

b

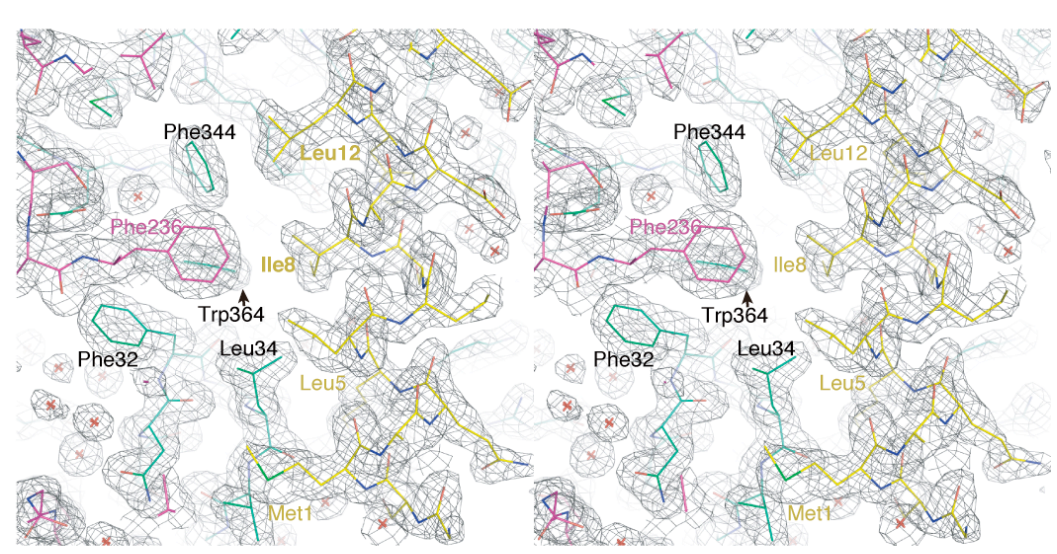

d

(a) The same ribbon presentation as in Fig. 1c, right. Boxes indicate the regions enlarged in (b, c, d). (b-d) Atomic models are shown as stick models. Oxygen atoms are colored red, nitrogen blue, sulfur green, and carbon atoms according to the peptide chain (Pex7p, lime green; Pex21pC, light magenta; Fox3pN, yellow). Electron-density maps $\left(2 F_{0}-F_{\mathrm{c}}\right.$ density contoured at $\left.1 \sigma\right)$ are shown as meshes. Residues are labeled according to the peptide chain (Pex7p, black; Pex21pC, light magenta; Fox3pN, yellow). 


\section{Supplementary Figure 4}

Single-molecule structures of Pex7p and Pex21pC.

a

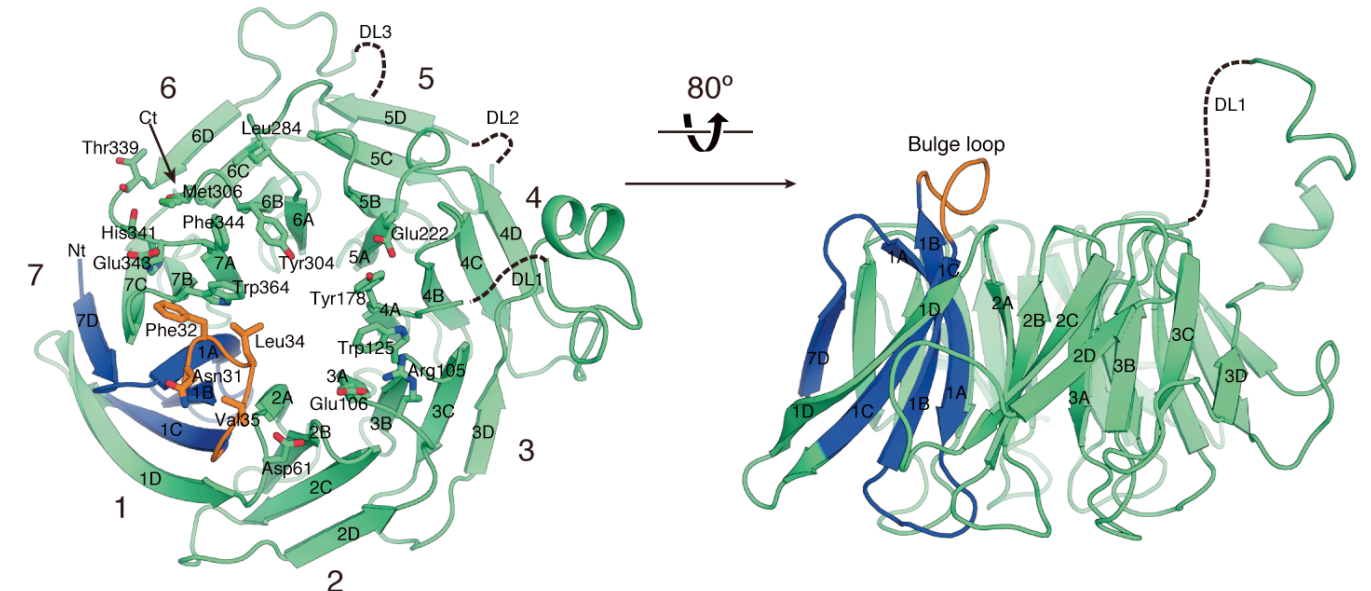

b

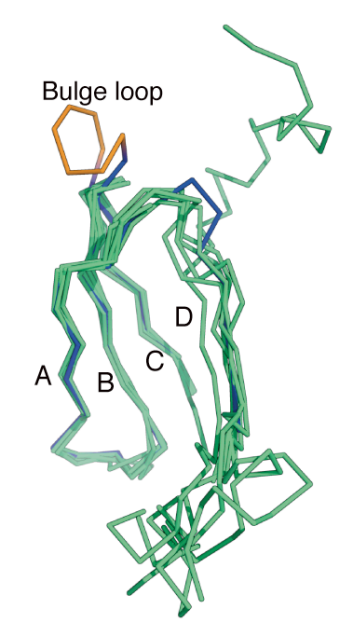

C

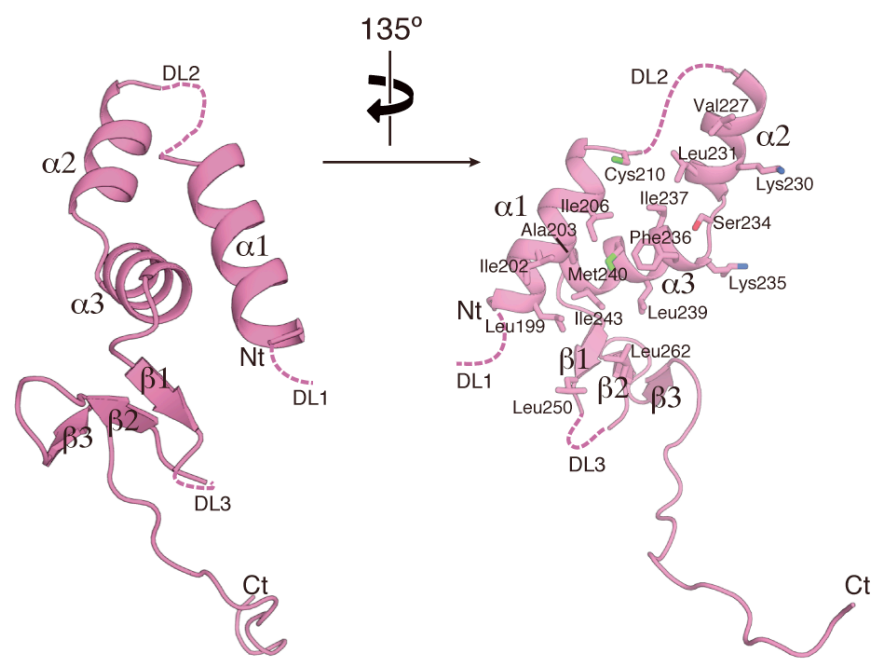

(a) Ribbon representation of Pex7p. The left molecule is in the same orientation as in Fig. 1c, right. (b) Structural alignment of the $\mathrm{N}$-terminal 44 residues (blue and orange) of Pex7p with the other six WD40 motifs (lime green). The main chains are traced as sticks. (c) Ribbon representation of Pex21pC. The left molecule is in the same orientation as in Fig. 1c, right. $\mathrm{Nt}$, $\mathrm{N}$-terminus; $\mathrm{Ct}$, C-terminus; $\mathrm{DL}$, disordered loop. 


\section{Supplementary Figure 5}

In vivo Fox3pN-EGFP transport assays.

a

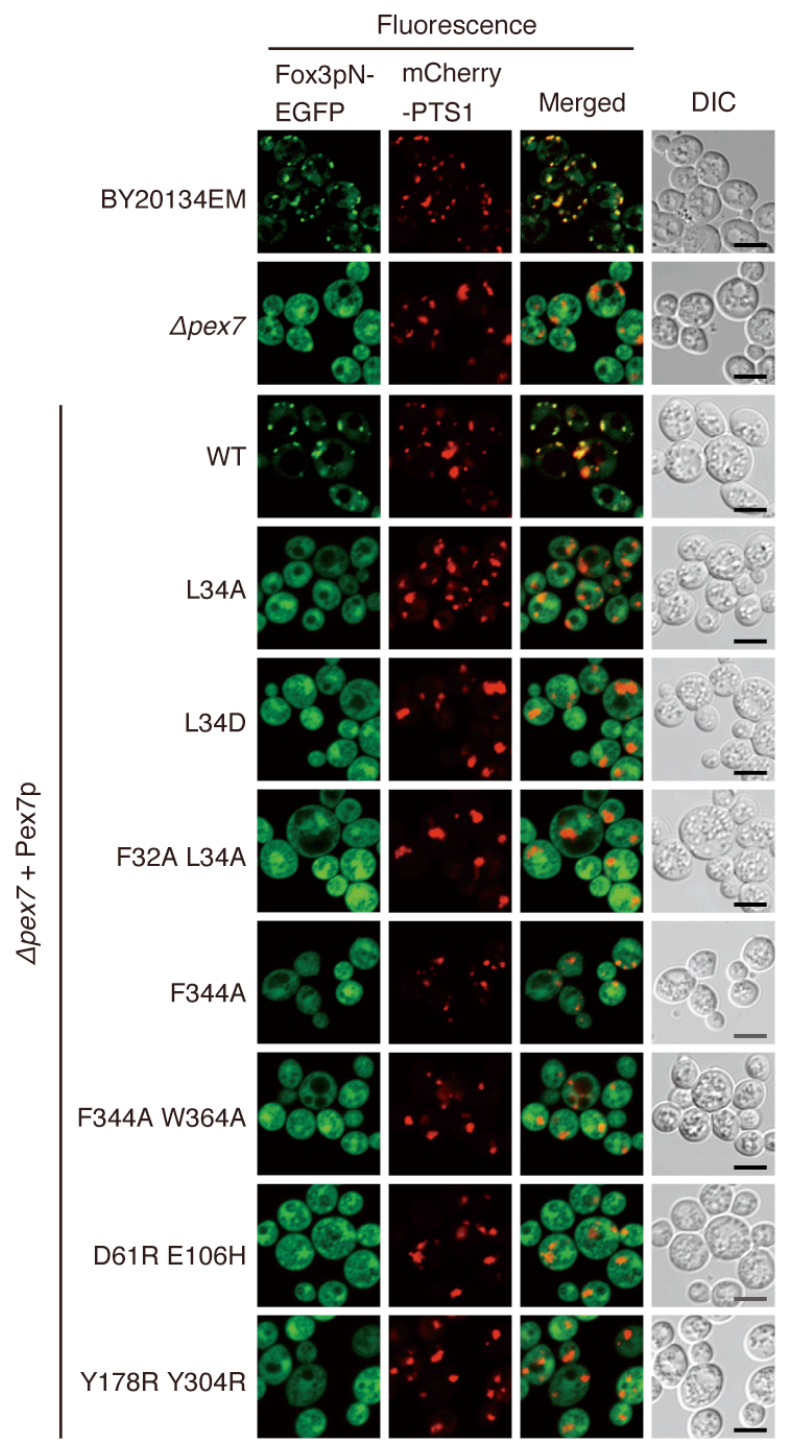

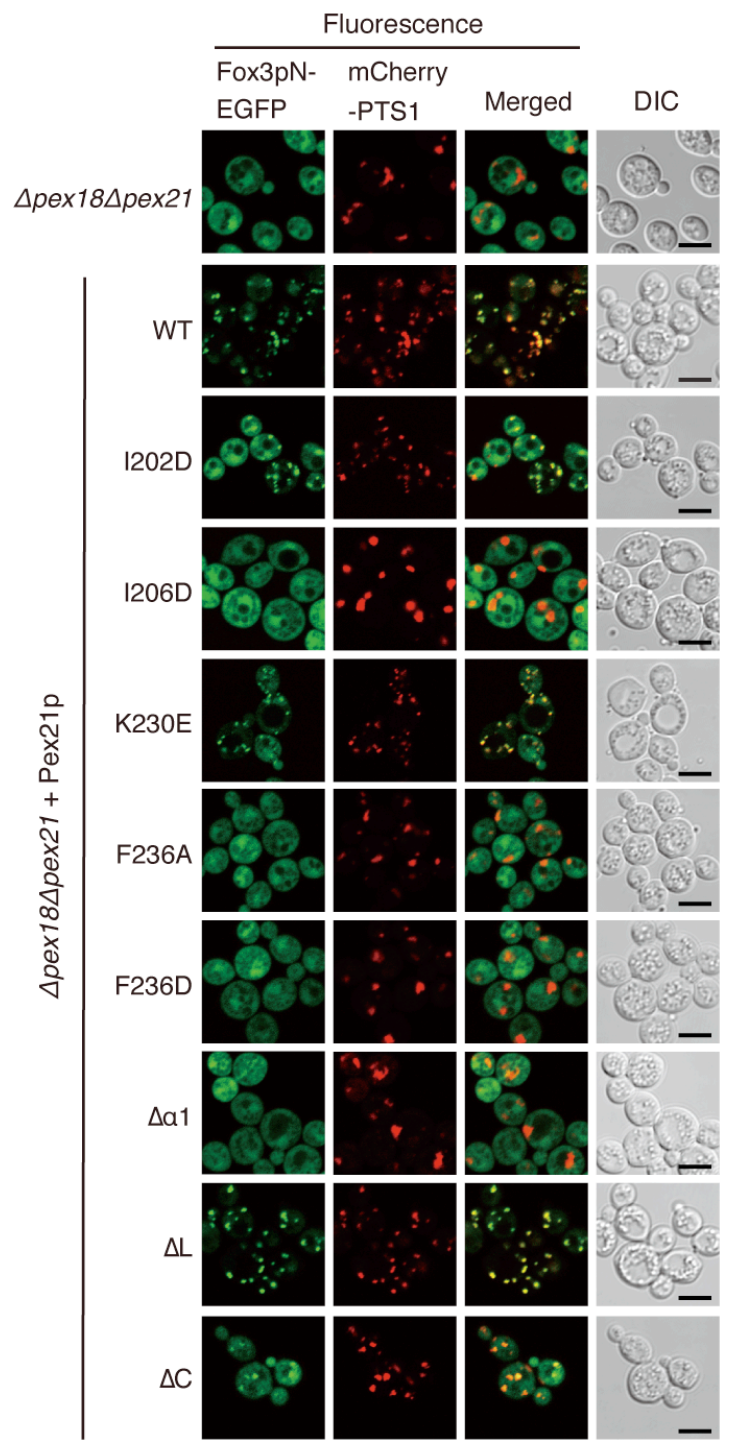

b

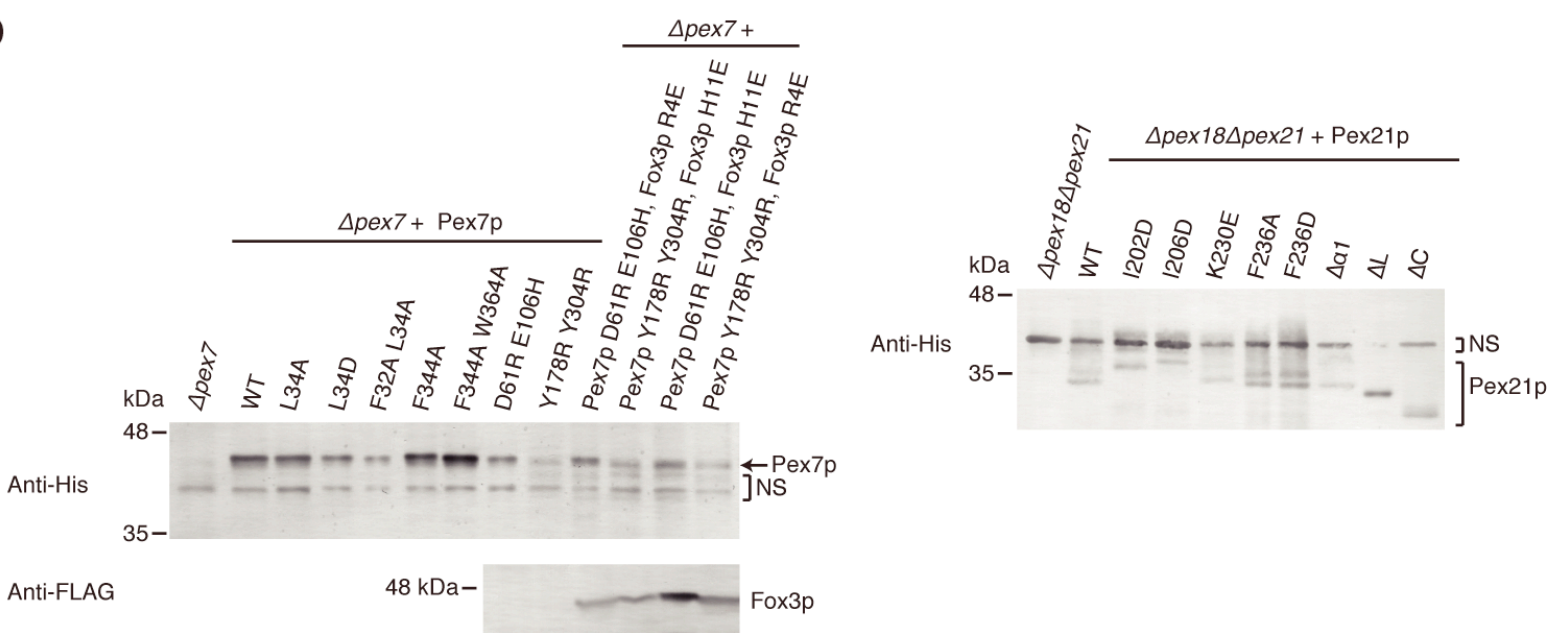


(a) The S. cerevisiae strains were grown in SCEO medium to an $\mathrm{OD}_{600}$ of 2 , and live cells were examined with a confocal fluorescence microscopy. The intracellular localizations of Fox3pN-EGFP and mCherry-PTS1 were visualized by their fluorescence. The red spots of mCherry-PTS1 indicate the locations of peroxisomes, and the yellow spots in the merged fluorescence image indicate the co-localization of Fox3pN-EGFP and mCherry-PTS1. The scale bars in the differential interference contrast (DIC) images represent $5 \mu \mathrm{m}$. (b) The expression levels of Pex7p, Pex21p, and Fox3p variants were confirmed by western blotting. Pex7p and Pex21p variants contained $\mathrm{His}_{6}$-tags at their $\mathrm{C}$-termini, and were detected by western blotting using penta-His-specific HRP conjugate antibody. Fox3p variants contained FLAG-tags at their C-termini, and were detected using FLAG-specific antibody. NS indicates non-specific $S$. cerevisiae proteins, which bound to Ni-IMAC resin and were detected by the penta-His-specific HRP conjugate antibody. WT, wild type. 


\section{Supplementary Table 1}

Plasmids used in this study.

\begin{tabular}{|c|c|c|}
\hline Plasmid & Description & Source \\
\hline pAG425GPD-ccdB-HA & LEU2, $2 \mu, A m p^{R}$ & Addgene \\
\hline pAG426GPD-ccdB-HA & URA3, $2 \mu, A m p^{R}$ & Addgene \\
\hline pAG304GPD-ccdB-EGFP & $T R P 1, A m p^{R}$ & Addgene \\
\hline pAG303GPD-ccdB-HA & $H I S 3, A m p^{R}$ & Addgene \\
\hline pmCherry & $A m p^{R}$, mCherry-tag & Clontech \\
\hline $\begin{array}{l}\text { pAG304-Fox3pN-EGFP/mCherry- } \\
\text { PTS1 }\end{array}$ & $\begin{array}{l}\text { FOX3 promoter driving FOX3N-EGFP, GPD } \\
\text { promoter driving } M C H E R R Y-S K L, T R P 1, A m p^{R}\end{array}$ & This study \\
\hline pAG425-Pex7p & $\begin{array}{l}P E X 7 \text { promoter driving } P E X 7-H i s_{6}, L E U 2,2 \mu \text {, } \\
A m p^{R}\end{array}$ & This study \\
\hline pAG425-Pex7p(L34A) & $\begin{array}{l}\text { PEX7 promoter driving } \operatorname{pex} 7(L 34 A)-H i s_{6}, L E U 2, \\
2 \mu, A m p^{R}\end{array}$ & This study \\
\hline pAG425-Pex7p(L34D) & $\begin{array}{l}P E X 7 \text { promoter driving } \operatorname{pex} 7(L 34 D)-H i s_{6}, L E U 2, \\
2 \mu, A m p^{R}\end{array}$ & This study \\
\hline pAG425-Pex7p(F32A L34A) & $\begin{array}{l}\text { PEX7 promoter driving pex7(F32A L34A)-His } \text {, }_{6} \\
\text { LEU2, } 2 \mu, A m p^{R}\end{array}$ & This study \\
\hline pAG425-Pex7p(F344A) & $\begin{array}{l}\text { PEX7 promoter driving pex7(F344A)-His6, } \\
\text { LEU2, } 2 \mu, A m p^{R}\end{array}$ & This study \\
\hline pAG425-Pex7p(F344A W364A) & $\begin{array}{l}\text { PEX7 promoter driving } \operatorname{pex} 7(\mathrm{~F} 344 A \\
\text { W364A)-His }_{6}, L E U 2,2 \mu, A m p^{R}\end{array}$ & This study \\
\hline pAG425-Pex7p(D61R E106H) & $\begin{array}{l}\text { PEX7 promoter driving pex7(D61R } \\
\text { E106H)-His } 6, \text { LEU2, } 2 \mu, A m p^{R}\end{array}$ & This study \\
\hline pAG425-Pex7p(Y178R Y304R) & $\begin{array}{l}\text { PEX7 promoter driving } \operatorname{pex} 7(Y 178 R \\
\text { Y304R)-His }, \text { LEU2, } 2 \mu, A m p^{R}\end{array}$ & This study \\
\hline pAG303-Fox3p & $\begin{array}{l}\text { FOX3 promoter driving FOX3-FLAG, HIS3, } \\
A m p^{R}\end{array}$ & This study \\
\hline pAG303-Fox3p(R4E) & $\begin{array}{l}\text { FOX3 promoter driving fox3(R4E)-FLAG, HIS3, } \\
A m p^{R}\end{array}$ & This study \\
\hline
\end{tabular}




\begin{tabular}{|c|c|c|}
\hline pAG303-Fox3p(H11E) & $\begin{array}{l}\text { FOX3 promoter driving fox3(H11E)-FLAG, } \\
\text { HIS3, } A m p^{R}\end{array}$ & This study \\
\hline pAG426-Pex21p & $\begin{array}{l}\text { PEX21 promoter driving } P E X 21-H i s_{6}, \text { URA3, } \\
2 \mu, A m p^{R}\end{array}$ & This study \\
\hline pAG426-Pex21p(I202D) & $\begin{array}{l}\text { PEX21 promoter driving pex21(I202D)-His }{ }_{6} \\
\text { URA3, } 2 \mu, A m p^{R}\end{array}$ & This study \\
\hline pAG426-Pex21p(I206D) & $\begin{array}{l}\text { PEX21 promoter driving pex21(I206D)-His } \\
\text { URA3, } 2 \mu, A m p^{R}\end{array}$ & This study \\
\hline pAG426-Pex21p(K230E) & $\begin{array}{l}\text { PEX21 promoter driving pex21(K230E)-His } 6 \text {, } \\
\text { URA3, } 2 \mu, A m p^{R}\end{array}$ & This study \\
\hline pAG426-Pex21p(F236A) & $\begin{array}{l}\text { PEX21 promoter driving pex21(F236A)-His }{ }_{6}, \\
\text { URA3, } 2 \mu, A m p^{R}\end{array}$ & This study \\
\hline pAG426-Pex21p(F236D) & $\begin{array}{l}\text { PEX21 promoter driving pex21(F236D)-His } 6 \text {, } \\
\text { URA3, } 2 \mu, A m p^{R}\end{array}$ & This study \\
\hline pAG426-Pex21p $(\Delta 197-211)$ & $\begin{array}{l}\text { PEX21 promoter driving pex21( } \Delta 197-211)-H_{i s_{6}} \\
\text { URA3, } 2 \mu, A m p^{R}\end{array}$ & This study \\
\hline pAG426-Pex21p $(\Delta 214-229)$ & $\begin{array}{l}\text { PEX21 promoter driving pex21( } \Delta 214-229)-H i s_{6} \text {, } \\
\text { URA3, } 2 \mu, A m p^{R}\end{array}$ & This study \\
\hline pAG426-Pex21p $(\Delta 247-288)$ & $\begin{array}{l}\text { PEX21 promoter driving pex21( } \Delta 247-288)-H i s_{6}, \\
\text { URA3, } 2 \mu, A m p^{R}\end{array}$ & This study \\
\hline pPICZA & Zeocin $^{R}$ & Invitrogen \\
\hline pGEX-6P-1 & $A m p^{R}$, GST-tag, PreScission protease site & $\begin{array}{l}\text { GE } \\
\text { Healthcare }\end{array}$ \\
\hline pMAL-c2E & $A m p^{R}$, MBP2-tag, Enterokinase site & NEB \\
\hline pGEX6PT & $\begin{array}{l}A m p^{R}, \text { GST-tag, PreScission protease site, TEV } \\
\text { protease site }\end{array}$ & This study \\
\hline pGEX6PT-Pex7p & tac promoter driving GST-PEX7, $A m p^{R}$ & This study \\
\hline pGEX6PT-Pex21pC & tac promoter driving GST-PEX21C, $A m p^{R}$ & This study \\
\hline pGEX6PT-Fox3p & tac promoter driving GST-FOX3, $A m p^{R}$ & This study \\
\hline pGEX6PT-Fox3pN-MBP & tac promoter driving GST-FOX3N-MBP, Amp ${ }^{R}$ & This study \\
\hline
\end{tabular}




\begin{tabular}{|c|c|c|}
\hline pPICZA-GST-Pex7p & $A O X 1$ promoter driving GST-PEX7, Zeocin ${ }^{R}$ & This study \\
\hline pPICZA-GST-Pex7p $(\Delta 257-265)$ & $\begin{array}{l}\text { AOX1 promoter driving GST-PEX7( } \triangle 257-265) \text {, } \\
\text { Zeocin }^{R}\end{array}$ & This study \\
\hline pPICZA-GST-Pex7p(F32A) & $\begin{array}{l}\text { AOX1 promoter driving GST-PEX7(F32A), } \\
\text { Zeocin }^{R}\end{array}$ & This study \\
\hline pPICZA-GST-Pex7p(L34A) & $\begin{array}{l}\text { AOX1 promoter driving GST-PEX7(L34A), } \\
Z_{\text {Zeocin }}^{R}\end{array}$ & This study \\
\hline pPICZA-GST-Pex7p(L34D) & $\begin{array}{l}\text { AOX1 promoter driving GST-PEX7(L34D), } \\
\text { Zeocin }^{R}\end{array}$ & This study \\
\hline pPICZA-GST-Pex7p(F32A L34A) & $\begin{array}{l}\text { AOX1 promoter driving GST-PEX7(F32A } \\
L 34 A), \text { Zeocin }^{R}\end{array}$ & This study \\
\hline pPICZA-GST-Pex7p(F344A) & $\begin{array}{l}\text { AOX1 promoter driving GST-PEX7(F344A), } \\
\text {Zeocin }^{R}\end{array}$ & This study \\
\hline $\begin{array}{l}\text { pPICZA-GST-Pex7p(F344A } \\
\text { W364A) }\end{array}$ & $\begin{array}{l}\text { AOX1 promoter driving GST-PEX7(F344A } \\
W 364 A), Z^{2 e o c i n}{ }^{R}\end{array}$ & This study \\
\hline pMEXT-Pex21pC & tac promoter driving $M B P-P E X 21 C-H i s_{6}, A m p^{R}$ & This study \\
\hline pMEXT-Pex21pC(I202D) & $\begin{array}{l}\text { tac promoter driving MBP-PEX21C(I202D)-His }{ }_{6} \text {, } \\
\text { Amp }^{R}\end{array}$ & This study \\
\hline pMEXT-Pex21pC(I206D) & $\begin{array}{l}\text { tac promoter driving MBP-PEX21C(I206D)-His } \\
\text { Amp }^{R}\end{array}$ & This study \\
\hline pMEXT-Pex21pC(K230E) & $\begin{array}{l}\text { tac promoter driving } \\
M B P-P E X 21 C(K 230 E)-H i s_{6}, A m p^{R}\end{array}$ & This study \\
\hline pMEXT-Pex21pC(F236A) & $\begin{array}{l}\text { tac promoter driving } \\
M B P-P E X 21 C(F 236 A)-H i s_{6}, A m p^{R}\end{array}$ & This study \\
\hline pMEXT-Pex21pC(F236D) & $\begin{array}{l}\text { tac promoter driving } \\
M B P-P E X 21 C(F 236 D)-H i s_{6}, A m p^{R}\end{array}$ & This study \\
\hline pMEXT-Pex21pC( $(197-211)$ & $\begin{array}{l}\text { tac promoter driving } \\
\text { MBP-PEX21C(D197-211)-His } 6, A m p^{R}\end{array}$ & This study \\
\hline pMEXT-Pex21pC( $\Delta 214-229)$ & $\begin{array}{l}\text { tac promoter driving } \\
\text { MBP-PEX21C(D214-229)-His } 6, A m p^{R}\end{array}$ & This study \\
\hline pMEXT-Pex21pC( $\Delta 247-288)$ & $\begin{array}{l}\text { tac promoter driving } \\
M B P-P E X 21 C(\triangle 247-288)-H i s_{6}, A m p^{R}\end{array}$ & This study \\
\hline
\end{tabular}




\section{Supplementary Table 2}

Yeast strains used in this study.

\begin{tabular}{|c|c|c|}
\hline S. cerevisiae Strain & Genotype & Source \\
\hline BY20134 (W303-1A) & $\begin{array}{l}\text { MATa; ade2-1; can1-100; his3-11,15; leu2-3,112; trp1-1; } \\
\text { ura3-1; rad5-535 }\end{array}$ & NBRP \\
\hline BY20134EM & $\begin{array}{l}\text { MATa; ade2-1; can1-100; his3-11,15; leu2-3,112; trp1-1; } \\
\text { ura3-1; rad5-535; } \\
\text { [pAG304-Fox3pN-EGFP/mCherry-PTS1] }\end{array}$ & This study \\
\hline$\Delta p e x 7$ & $\begin{array}{l}\text { MATa; ade2-1; can1-100; his3-11,15; leu2-3,112; trp1-1; } \\
\text { ura3-1; rad5-535; pex7::URA3; } \\
\text { [pAG304-Fox3pN-EGFP/mCherry-PTS1] }\end{array}$ & This study \\
\hline$\Delta p e x 18 \Delta p e \times 21$ & $\begin{array}{l}\text { MATa; ade2-1; can1-100; his3-11,15; leu2-3,112; trp1-1; } \\
\text { ura3-1; rad5-535; pex18::HIS3; pex21::LEU2; } \\
\text { [pAG304-Fox3pN-EGFP/mCherry-PTS1] }\end{array}$ & This study \\
\hline$\Delta p e x 7+\operatorname{Pex} 7 p$ WT & $\begin{array}{l}\text { MATa; ade2-1; can1-100; his3-11,15; leu2-3,112; trp1-1; } \\
\text { ura3-1; rad5-535; pex7::URA3; } \\
\text { [pAG304-Fox3pN-EGFP/mCherry-PTS1], } \\
\text { [pAG425-Pex7p)] }\end{array}$ & This study \\
\hline $\begin{array}{l}\Delta p e x 7+ \\
\text { Pex7p L34A }\end{array}$ & $\begin{array}{l}\text { MATa; ade2-1; can1-100; his3-11,15; leu2-3,112; trp1-1; } \\
\text { ura3-1; rad5-535; pex7::URA3; } \\
\text { [pAG304-Fox3pN-EGFP/mCherry-PTS1)], } \\
\text { [pAG425-Pex7p(L34A)] }\end{array}$ & This study \\
\hline $\begin{array}{l}\Delta p e x 7+ \\
\text { Pex7p L34D }\end{array}$ & $\begin{array}{l}\text { MATa; ade2-1; can1-100; his3-11,15; leu2-3,112; trp1-1; } \\
\text { ura3-1; rad5-535; pex7::URA3; } \\
\text { [pAG304-Fox3pN-EGFP/mCherry-PTS1], } \\
\text { [pAG425-Pex7p(L34D)] }\end{array}$ & This study \\
\hline $\begin{array}{l}\triangle p e x 7+ \\
\text { Pex7p F32A L34A }\end{array}$ & $\begin{array}{l}\text { MATa; ade2-1; can1-100; his3-11,15; leu2-3,112; trp1-1; } \\
\text { ura3-1; rad5-535; pex7::URA3; } \\
\text { [pAG304-Fox3pN-EGFP/mCherry-PTS1], } \\
\text { [pAG425-Pex7p(F32A L34A)] }\end{array}$ & This study \\
\hline $\begin{array}{l}\Delta p e x 7+ \\
\text { Pex7p F344A }\end{array}$ & $\begin{array}{l}\text { MATa; ade2-1; can1-100; his3-11,15; leu2-3,112; trp1-1; } \\
\text { ura3-1; rad5-535; pex7::URA3; } \\
\text { [pAG304-Fox3pN-EGFP/mCherry-PTS1], } \\
\text { [pAG425-Pex7p(F344A)] }\end{array}$ & This study \\
\hline
\end{tabular}




\begin{tabular}{|c|c|c|}
\hline $\begin{array}{l}\Delta p e x 7+ \\
\text { Pex7p F344A W364A }\end{array}$ & $\begin{array}{l}\text { MATa; ade2-1; can1-100; his3-11,15; leu2-3,112; trp1-1; } \\
\text { ura3-1; rad5-535; pex7::URA3; } \\
\text { [pAG304-Fox3pN-EGFP/mCherry-PTS1], } \\
\text { [pAG425-Pex7p(F344A W364A)] }\end{array}$ & This study \\
\hline $\begin{array}{l}\Delta p e x 7+ \\
\text { Pex7p D61R E106H }\end{array}$ & $\begin{array}{l}\text { MATa; ade2-1; can1-100; his3-11,15; leu2-3,112; trp1-1; } \\
\text { ura3-1; rad5-535; pex7::URA3; } \\
\text { [pAG304-Fox3pN-EGFP/mCherry-PTS1], } \\
\text { [pAG425-Pex7p(D61R E106H)] }\end{array}$ & This study \\
\hline $\begin{array}{l}\Delta p e x 7+ \\
\text { Pex7p Y178R Y304R }\end{array}$ & $\begin{array}{l}\text { MATa; ade2-1; can1-100; his3-11,15; leu2-3,112; trp1-1; } \\
\text { ura3-1; rad5-535; pex7::URA3; } \\
\text { [pAG304-Fox3pN-EGFP/mCherry-PTS1], } \\
\text { [pAG425-Pex7p(Y178R Y304R)] }\end{array}$ & This study \\
\hline $\begin{array}{l}\Delta p e x 7+ \\
\text { Pex7p D61R E106H, } \\
\text { Fox3p R4E }\end{array}$ & $\begin{array}{l}\text { MATa; ade2-1; can1-100; his3-11,15; leu2-3,112; trp1-1; } \\
\text { ura3-1; rad5-535; pex7::URA3; } \\
\text { [pAG304-Fox3pN-EGFP/mCherry-PTS1], } \\
\text { [pAG425-Pex7p(D61R E106H)], [pAG303-Fox3p(R4E)] }\end{array}$ & This study \\
\hline $\begin{array}{l}\Delta p e x 7+ \\
\text { Pex7p Y178R Y304R, } \\
\text { Fox3p H11E }\end{array}$ & $\begin{array}{l}\text { MATa; ade2-1; can1-100; his3-11, 15; leu2-3,112; trp1-1; } \\
\text { ura3-1; rad5-535; pex7::URA3; } \\
\text { [pAG304-Fox3pN-EGFP/mCherry-PTS1], } \\
\text { [pAG425-Pex7p(Y178R Y304R)], [pAG303-Fox3p(H11E)] }\end{array}$ & This study \\
\hline $\begin{array}{l}\Delta p e x 7+ \\
\text { Pex7p D61R E106H, } \\
\text { Fox3p H11E }\end{array}$ & $\begin{array}{l}\text { MATa; ade2-1; can1-100; his3-11,15; leu2-3,112; trp1-1; } \\
\text { ura3-1; rad5-535; pex7::URA3; } \\
\text { [pAG304-Fox3pN-EGFP/mCherry-PTS1], } \\
\text { [pAG425-Pex7p(D61R E106H)], [pAG303-Fox3p(H11E)] }\end{array}$ & This study \\
\hline $\begin{array}{l}\Delta p e x 7+ \\
\text { Pex7p Y178R Y304R, } \\
\text { Fox3p R4E }\end{array}$ & $\begin{array}{l}\text { MATa; ade2-1; can1-100; his3-11,15; leu2-3,112; trp1-1; } \\
\text { ura3-1; rad5-535; pex7::URA3; } \\
\text { [pAG304-Fox3pN-EGFP/mCherry-PTS1], } \\
\text { [pAG425-Pex7p(Y178R Y304R)], [pAG303-Fox3p(R4E)] }\end{array}$ & This study \\
\hline $\begin{array}{l}\Delta p e x 18 \Delta p e x 21+\text { Pex21p } \\
\text { WT }\end{array}$ & $\begin{array}{l}\text { MATa; ade2-1; can1-100; his3-11,15; leu2-3,112; trp1-1; } \\
\text { ura3-1; rad5-535; pex18::HIS3; pex21::LEU2; } \\
\text { [pAG304-Fox3pN-EGFP/mCherry-PTS1], } \\
\text { [pAG426-Pex21p] }\end{array}$ & This study \\
\hline
\end{tabular}




\begin{tabular}{|c|c|c|}
\hline $\begin{array}{l}\Delta p e x 18 \Delta p e x 21+P e x 21 p \\
\text { I202D }\end{array}$ & $\begin{array}{l}\text { MATa; ade2-1; can1-100; his3-11,15; leu2-3,112; trp1-1; } \\
\text { ura3-1; rad5-535; pex18::HIS3; pex21::LEU2; } \\
\text { [pAG304-Fox3pN-EGFP/mCherry-PTS1], } \\
\text { [pAG426-Pex21p(I202D)] }\end{array}$ & This study \\
\hline $\begin{array}{l}\Delta p e x 18 \Delta p e x 21+P e x 21 p \\
\text { I206D }\end{array}$ & $\begin{array}{l}\text { MATa; ade2-1; can1-100; his3-11,15; leu2-3,112; trp1-1; } \\
\text { ura3-1; rad5-535; pex18::HIS3; pex21::LEU2; } \\
\text { [pAG304-Fox3pN-EGFP/mCherry-PTS1], } \\
\text { [pAG426-Pex21p(I206D)] }\end{array}$ & This study \\
\hline $\begin{array}{l}\Delta p e x 18 \Delta p e x 21+\text { Pex21p } \\
\text { K230E }\end{array}$ & $\begin{array}{l}\text { MATa; ade2-1; can1-100; his3-11,15; leu2-3,112; trp1-1; } \\
\text { ura3-1; rad5-535; pex18::HIS3; pex21::LEU2; } \\
\text { [pAG304-Fox3pN-EGFP/mCherry-PTS1], } \\
\text { [pAG426-Pex21p(K230E)] }\end{array}$ & This study \\
\hline $\begin{array}{l}\Delta p e x 18 \Delta p e x 21+P e x 21 p \\
F 236 A\end{array}$ & $\begin{array}{l}\text { MATa; ade2-1; can1-100; his3-11,15; leu2-3,112; trp1-1; } \\
\text { ura3-1; rad5-535; pex18::HIS3; pex21::LEU2; } \\
\text { [pAG304-Fox3pN-EGFP/mCherry-PTS1], } \\
\text { [pAG426-Pex21p(F236A)] }\end{array}$ & This study \\
\hline $\begin{array}{l}\Delta p e x 18 \Delta p e x 21+\text { Pex21p } \\
\text { F236D }\end{array}$ & $\begin{array}{l}\text { MATa; ade2-1; can1-100; his3-11, 15; leu2-3,112; trp1-1; } \\
\text { ura3-1; rad5-535; pex18::HIS3; pex21::LEU2; } \\
\text { [pAG304-Fox3pN-EGFP/mCherry-PTS1], } \\
\text { [pAG426-Pex21p(F236D)] }\end{array}$ & This study \\
\hline $\begin{array}{l}\Delta p e x 18 \Delta p e x 21+P e x 21 p \\
\Delta a 1(\Delta 197-211)\end{array}$ & $\begin{array}{l}\text { MATa; ade2-1; can1-100; his3-11,15; leu2-3,112; trp1-1; } \\
\text { ura3-1; rad5-535; pex18::HIS3; pex21::LEU2; } \\
\text { [pAG304-Fox3pN-EGFP/mCherry-PTS1] } \\
\text { [pAG426-Pex21p(D197-211)] }\end{array}$ & This study \\
\hline $\begin{array}{l}\Delta p e x 18 \Delta p e x 21+\text { Pex21p } \\
\Delta L(\Delta 214-229)\end{array}$ & $\begin{array}{l}\text { MATa; ade2-1; can1-100; his3-11,15; leu2-3,112; trp1-1; } \\
\text { ura3-1; rad5-535; pex18::HIS3; pex21::LEU2; } \\
\text { [pAG304-Fox3pN-EGFP/mCherry-PTS1] } \\
\text { [pAG426-Pex21p(D214-229)] }\end{array}$ & This study \\
\hline $\begin{array}{l}\Delta p e x 18 \Delta p e x 21+\operatorname{Pex} 21 p \\
\Delta C(\Delta 247-288)\end{array}$ & $\begin{array}{l}\text { MATa; ade2-1; can1-100; his3-11,15; leu2-3,112; trp1-1; } \\
\text { ura3-1; rad5-535; pex18::HIS3; pex21::LEU2; } \\
\text { [pAG304-Fox3pN-EGFP/mCherry-PTS1], } \\
\text { [pAG426-Pex21p(D247-288)] }\end{array}$ & This study \\
\hline
\end{tabular}




\begin{tabular}{|c|c|c|}
\hline P. pastoris Strain & Genotype & Source \\
\hline SMD1163 & his4; pep4; prb1 & Invitrogen \\
\hline SMD1163 + GST-Pex7p & his4; pep4; prb1; [pPICZA-GST-Pex7p] & This study \\
\hline $\begin{array}{l}\text { SMD1163 + } \\
\text { GST-Pex7p }(\Delta 257-265)\end{array}$ & his4; pep4; prb1; [pPICZA-GST-Pex7p( $\Delta 257-265)]$ & This study \\
\hline $\begin{array}{l}\text { SMD1163 + } \\
\text { GST-Pex7p(F32A) }\end{array}$ & his4; pep4; prb1; [pPICZA-GST-Pex7p(F32A)] & This study \\
\hline $\begin{array}{l}\text { SMD1163 + } \\
\text { GST-Pex7p(L34A) }\end{array}$ & his4; pep4; prb1; [pPICZA-GST-Pex7p(L34A)] & This study \\
\hline $\begin{array}{l}\text { SMD1163 + } \\
\text { GST-Pex7p(L34D) }\end{array}$ & his4; pep4; prb1; [pPICZA-GST-Pex7p(L34D)] & This study \\
\hline $\begin{array}{l}\text { SMD1163 + } \\
\text { GST-Pex7p(F32A L34A) }\end{array}$ & his4; pep4; prb1; [pPICZA-GST-Pex7p(F32A L34A)] & This study \\
\hline $\begin{array}{l}\text { SMD1163 + } \\
\text { GST-Pex7p(F344A) }\end{array}$ & his4; pep4; prb1; [pPICZA-GST-Pex7p(F344A)] & This study \\
\hline $\begin{array}{l}\text { SMD1163 + } \\
\text { GST-Pex7p(F344A } \\
\text { W364A) }\end{array}$ & his4; pep4; prb1; [pPICZA-GST-Pex7p(F344A W364A)] & This study \\
\hline
\end{tabular}




\section{Supplementary Note}

\section{Plasmids}

Escherichia coli expression plasmids for expression of Pex21pC, Fox3p, and Fox3pN-MBP as TEV-cleavable N-terminal GST-tagged proteins were constructed as follows. Expression vector pGEX6PT was created by modifying pGEX-6P-1 (GE Healthcare) by inserting a sequence (5'-GGATCTGGTACCGAAAACCTG TACTTCCAG-3') that encodes linker residues (Gly-Ser-Gly-Thr) and a TEV protease cleavage site (Glu-Asn-Leu-Tyr-Phe-GIn), immediately upstream of the BamHI site of pGEX-6P-1. Coding sequences of Saccharomyces cerevisiae Pex21pC and Fox3p were amplified by PCR from yeast genomic DNA and inserted between the BamHI and Sall sites of pGEX6PT to obtain pGEX6PT-Pex21pC and pGEX6PT-Fox3p. Expression vector pGEX6PT-Fox3pN-MBP was constructed by replacing the coding sequence of Fox3p residues 16-417 of pGEX6PT-Fox3p with a linker (5'-AGATCC-3') followed by the coding sequence of $E$. coli MalE residues 27-396 (MBP), which was cloned from E. coli BL21(DE3) (Invitrogen) genomic DNA.

Pichia pastoris expression plasmids for expression of TEV-cleavable $\mathrm{N}$-terminal GST-tagged Pex7p and its variants were constructed as follows. The coding sequence of $S$. cerevisiae Pex7p was amplified by PCR from $S$. cerevisiae genomic DNA and inserted between the BamHI and Sall sites of pGEX6PT. Next, the coding sequence of GST-Pex7p from pGEX6PT-Pex7p was subcloned into the pPICZA expression vector (Invitrogen) between the EcoRI and Sall sites to yield pPICZA-GST-Pex7p. The plasmids for expression of Pex7p variants were created by site-directed mutagenesis of pPICZA-GST-Pex7p using a modified PCR method as described ${ }^{5}$.

E. coli plasmids for expression of C-terminally $\mathrm{His}_{6}$-tagged MBP-Pex21pC and its variants were constructed as follows. The plasmid pMEXT-Pex21pC was generated from pGEX6PT-Pex21pC by adding the coding sequence of the $\mathrm{His}_{6}$-tag after the coding sequence of Pex21pC using an modified inverse PCR method ${ }^{6}$ and exchanging the coding sequence of GST (5'-GTATTCATGTCCCCTATACT...TCCAGGGGCCCCTGGGATCT-3') for MBP 
(5'-CATATGAAAACTGAAGAAGG...ACAATAACAACAACGGGCCC-3'), which was subcloned from pMAL-c2E (NEB). Deletions and point mutations were introduced to pMEXT-Pex21pC using site-directed mutagenesis as described above.

S. cerevisiae plasmid pAG425-Pex7p was constructed by amplifying the PEX7 ORF plus 440 bp of upstream sequence from $S$. cerevisiae genomic DNA, inserting the resulting amplicon between the Sacl and Hindll sites of pAG425GPD-ccdB-HA ${ }^{7}$ (Addgene), and replacing the coding sequence of the $\mathrm{HA}_{3}$-tag (5'-ATGTACCCATACGATGTTCCTGACTATGCGGGCTATCCCTATGACGTCCCGG ACTATGCAGGATCCTATCCATATGACGTTCCAGATTACGCTGCTCAGTGC-3') with that of the His $_{6}$-tag (5'-CATCATCATCATCATCAT-3') by the inverse PCR method described above. Likewise, pAG426-Pex21p was constructed by amplifying the PEX21 ORF plus 520 bp of upstream sequence, inserting this amplicon between the Sacl and Hindll sites of pAG426GPD-ccdB-HA ${ }^{7}$ (Addgene), and replacing the coding sequence of the $\mathrm{HA}_{3}$-tag with that of the $\mathrm{His}_{6}$-tag. Expression of $\mathrm{His}_{6}$-tagged Pex7p and Pex21p was regulated under control of their original promoters and the $C Y C 1$ terminator. Plasmids expressing variants of Pex7p and Pex21p were generated by the site-directed mutagenesis described above.

S. cerevisiae integrating plasmid pAG303-Fox3p was constructed by amplifying the FOX3 ORF plus 380 bp of upstream sequence from $S$. cerevisiae genomic DNA, inserting this amplicon between the Sacl and Xhol sites of pAG303GPD-ccdB-HA ${ }^{7}$ (Addgene), and inserting the coding sequence of FLAG-tag (5'-GATTATAAAGATGAT GATGATAAG-3') after the coding sequence of Fox3p by the inverse PCR method described above. Plasmids expressing the variants of Fox3p were generated by the site-directed mutagenesis described above.

Bicistronic

$S$.

cerevisiae

integrating

plasmid pAG304-Fox3pN-EGFP/mCherry-PTS1 was constructed to enable simultaneous expression of Fox3pN-EGFP and mCherry-SKL. This plasmid was generated by replacing the DNA sequence between Sacl and Kpnl site of pAG304GPD-ccdB-EGFP $^{7}$ (Addgene) with tandem expression cassettes for Fox3pN-EGFP and mCherry-SKL. The coding sequence of Fox3pN-EGFP was placed 
between the $S$. cerevisiae FOX3 promoter (upstream 380-bp regulatory region of FOX3) and the CYC1 terminator, and the coding sequence of mCherry-SKL was placed between GPD promoter and the CYC1 terminator. The cDNA of mCherry was amplified from the pmCherry vector (Clontech).

All the constructs were verified by DNA sequencing before being used for protein expression. The list of all plasmids used in this study is presented in Supplementary Table 1.

\section{Western blotting}

S. cerevisiae cells $(0.2 \mathrm{~g})$ grown in SCEO medium $(0.67 \%$ yeast nitrogen base with ammonium sulfate without amino acids, $2 \%(\mathrm{v} / \mathrm{v})$ ethanol, $0.1 \%(\mathrm{w} / \mathrm{v})$ oleic acid, $0.4 \%(w / v)$ Tween 40, appropriate amino acids, uracil, and adenine) to an $\mathrm{OD}_{600}$ of 2 were suspended in $300 \mu$ l buffer B (30 mM Tris- $\mathrm{HCl}$ pH 7.5, 300 mM NaCl, 1 mM DTT) containing $1 \mathrm{mM}$ PMSF and lysed by vortexing with glass beads. Cleared lysate (350 $\mu \mathrm{l})$ was supplemented with imidazole to a concentration of $20 \mathrm{mM}$ and incubated with $15 \mu \mathrm{l} \mathrm{Ni-IMAC}$ resin for $1 \mathrm{~h}$ at $4^{\circ} \mathrm{C}$. After washing the resin three times with $500 \mu \mathrm{l}$ buffer B containing $20 \mathrm{mM}$ imidazole, proteins were eluted with $20 \mu \mathrm{l}$ buffer B

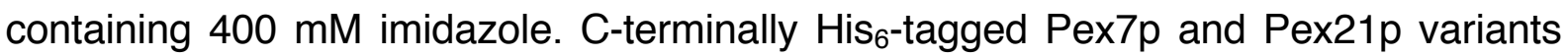
were detected by subjecting $5 \mu$ l eluted fraction to SDS-PAGE and western blotting using Penta-His HRP Conjugate (QIAGEN). C-terminally FLAG-tagged Fox3p variants were detected by subjecting cell lysate containing $30 \mu \mathrm{g}$ protein to SDS-PAGE and western blotting using anti-FLAG antibody M2 (Sigma) and anti-mouse IgG HRP-linked antibody (GE Healthcare). 


\section{References for Supplementary materials}

1. Thompson, J.D., Higgins, D.G. \& Gibson, T.J. CLUSTAL W: improving the sensitivity of progressive multiple sequence alignment through sequence weighting, position-specific gap penalties and weight matrix choice. Nucleic Acids Res. 22, 4673-4680 (1994).

2. Braverman, N. et al. Mutation analysis of PEX7 in 60 probands with rhizomelic chondrodysplasia punctata and functional correlations of genotype with phenotype. Hum. Mutat. 20, 284-297 (2002).

3. Motley, A.M. et al. Mutational spectrum in the PEX7 gene and functional analysis of mutant alleles in 78 patients with rhizomelic chondrodysplasia punctata type 1. Am. J. Hum. Genet. 70, 612-624 (2002).

4. Rehling, $P$. et al. The import receptor for the peroxisomal targeting signal 2 (PTS2) in Saccharomyces cerevisiae is encoded by the PAS7 gene. EMBO J. 15, 2901-2913 (1996).

5. Sawano, A. \& Miyawaki, A. Directed evolution of green fluorescent protein by a new versatile PCR strategy for site-directed and semi-random mutagenesis. Nucleic Acids Res. 28, E78 (2000).

6. Erster, O. \& Liscovitch, M. A modified inverse PCR procedure for insertion, deletion, or replacement of a DNA fragment in a target sequence and its application in the ligand interaction scan method for generation of ligand-regulated proteins. Methods Mol. Biol. 634, 157-174 (2010).

7. Alberti, S., Gitler, A.D. \& Lindquist, S. A suite of Gateway cloning vectors for high-throughput genetic analysis in Saccharomyces cerevisiae. Yeast 24, 913-919 (2007). 